\title{
A Review of Microstructural Evolution and Modelling of Aluminium Alloys under Hot Forming Conditions
}

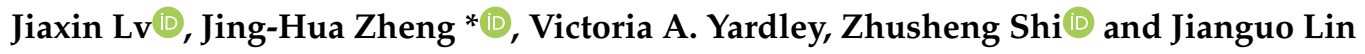 \\ Department of Mechanical Engineering, Imperial College London, London SW7 2AZ, UK; \\ j.lv19@imperial.ac.uk (J.L.); v.yardley@imperial.ac.uk (V.A.Y.); zhusheng.shi@imperial.ac.uk (Z.S.); \\ jianguo.lin@imperial.ac.uk (J.L.) \\ * Correspondence: jinghua.zheng13@imperial.ac.uk; Tel.: +44-(0)79-2208-7588
}

Received: 9 October 2020; Accepted: 13 November 2020; Published: 16 November 2020

\begin{abstract}
Microstructural evolution during hot forming of aluminium alloys plays a critical role in both the material flow behaviour during the deformation and the post-form mechanical properties in service. This paper presents a comprehensive review on the recrystallisation mechanisms, the interrelations between microstructures and macroscopic responses, and the associated modelling methods for aluminium alloys under hot forming conditions. Particular attention is focused on dynamic recrystallisation (DRX), which occurs during hot forming. The mechanisms, key features, and conditions of occurrence (forming temperature, strain rates, etc.) during hot forming for each type of DRX type are classified. The relationships between microstructures and macroscopic responses, including the flow behaviour, the post-form strength and ductility, are summarised based on existing experimental results. Most importantly, the associated modelling work, describing the recrystallisation and the viscoplastic behaviour under hot forming conditions, is grouped into four types, to enable a clear and concise understanding of the existing quantitative micro-macro interactions, which are particularly valuable for the future development of advanced physically based multi-scale modelling work for hot-forming processes in aluminium alloys.
\end{abstract}

Keywords: hot forming; recrystallisation; viscoplasticity; mechanical property; modelling; aluminium alloy

\section{Introduction}

Aluminium (Al) and its alloys are in the first rank of nonferrous materials for automotive, aerospace and marine applications thanks to their high specific strength, corrosion resistance and good thermal and electrical conductivity [1,2]. Hot deformation processes, such as hot rolling, hot extrusion, hot stamping and creep age forming, are commonly applied for forming Al components [3-6]. During these operations, microstructural processes of recrystallisation and grain growth, accompanied by dislocation accumulation and recovery [7] may occur and affect the formability. Furthermore, the final microstructures in a formed part, which may vary according to the location of the part, determine the post-forming mechanical properties, including strength, ductility and fatigue life [8,9]. Therefore, a deep understanding of the underlying microstructural evolution, the relationships between microscopic and macroscopic behaviour and the macroscopic responses of interest during hot deformation are vitally important for optimising the forming windows to achieve components with the desired geometries and in-service properties.

During hot forming, processes of dislocation evolution, dynamic recrystallisation (DRX) and grain growth [10] may occur, accompanied by evolutions in grain microstructure (boundary area and misorientation). These evolving microstructures determine the material flow behaviour. At low temperatures, dislocation generation and recovery affects the hardening and softening behaviour 
seen on stress-strain curves; this behaviour is well understood and follows the established plasticity theory. Under hot-forming conditions, where the deformation temperature is higher than $0.3 \times$ the absolute melting temperature, $T_{m}$, other effects come into play. Recrystallisation is triggered by the dynamic recovery of dislocations, leading to significant changes in the microstructures. These include consumption of the dislocations and formation of low-angle grain boundaries (LAGB), and high-angle grain boundaries (HAGB). Although significant research has been performed to understand the detailed evolution of microstructures during recrystallisation, this has focused only on specific materials under selective forming conditions, where one recrystallisation type is triggered. Three types of dynamic recrystallisation may occur for aluminium alloys, depending on the hot forming conditions, i.e., discontinuous, continuous and geometric dynamic recrystallisation (DDRX, CDRX, GDRX) [11,12], although CDRX is considered to be the most common type [13]. However, the microstructural evolutions, especially the conditions of occurrence for each recrystallisation type, are not fully understood. Additionally, a good overview of the microstructural changes in the presence of recrystallisation is still lacking. Furthermore, the effect of recrystallisation on post-forming grain sizes, which contribute to the strength, ductility and fatigue life, has not been reviewed, especially in the commercial aluminium alloys [14]. Although the Hall-Petch law [15] has been widely applied to describe the effect of grain size on the strength in Al alloys, the experimental results that demonstrate agreement with Hall-Petch are usually restricted within a selected range of either coarse or fine grain size.

Material modelling techniques to determine optimum hot deformation temperatures and strain rates have been developed since the 1900s. The earliest models to be proposed were empirical models relating to processing parameters and mechanical behaviour. However, the demonstrable dependence of macroscopic properties on microstructures indicates the importance of interpreting the mechanical properties from a microstructural viewpoint and of modelling the temporal evolution of microscopic features, among which dislocation density and grain size are the most important. Estrin et al. proposed a dislocation-based modelling method in 1998 to describe the dislocation evolution and flow stress response resulting from dislocation accumulation and recovery during deformation [16]. This model has subsequently been extended to consider the effects of recrystallisation [17] and grain size on viscoplastic behaviour [18]. Lin et al. presented a physically based modelling framework in 2005, which provided a feasible path to model the evolution of microstructures and micro-macro interactions [19,20]. Based on the guidance from this framework, scientists are able to select the critical microscopic state variables for specific research areas, for example, the subgrain rotation rate for recrystallisation analysis, and the nucleation rate of grain boundary cavities for damage analysis during deformation. However, all the abovementioned viscoplastic models are scattered in different literature and no effective classifications and summaries are yet available to systematise the modelling logic and support the future development of better viscoplastic models. A clear and systematic overview of existing models and the principles on which they are based is necessary so that these can be applied in an informed way to the prediction and control of Al alloy microstructural and mechanical behaviour during hot deformation.

Previous reviews have been carried out, focusing on specific aspects of recrystallisation. For example, dynamic recrystallisation and annealing behaviour after dynamic recrystallization was reviewed by Sakai et al. [21] in 2014 but GDRX was not covered. Huang and Loge [13] reviewed the basic recrystallisation mechanisms of metals in 2016; this review focused specifically on microstructures, without considering the resulting mechanical response. Although it included modelling methods, they were only briefly described without a detailed review. Additionally, their review focused on a wide range of metallic materials, without a specific consideration of $\mathrm{Al}$ alloys. The present review differs from the abovementioned work by comprehensively covering the microstructural features, quantitative microstructual evolutions, micro-macro relations and current physically- and non-physically-based constitutive models of aluminium alloys, which are the light alloys of the greatest industrial interest, especially for transportation industries. 
The main objective of this paper is to review the microstructural evolution during hot deformation in $\mathrm{Al}$ alloys and its role in determining the viscoplastic behaviour and post-forming properties, particularly in the case where dynamic recrystallisation occurs. The mechanisms and occurrence conditions of the three types of recrystallisation and of grain growth are separately described. The evolution of microstructural variables with strain, and the mechanical responses including strength, ductility and fatigue resistance, are summarised for different ranges of grain size. Four modelling types, describing the recrystallisation and the viscoplastic behaviour, are summarised. Final conclusions and suggestions for further research are given.

\section{Recrystallisation and Grain Growth under Hot Forming Conditions}

\subsection{Dynamic Recrystallisation Mechanisms and Conditions of Occurrence}

During the hot forming of aluminium alloys, dynamic recrystallisation may occur, leading to transformation of the original grains into new ones by consumption of the strain-hardened matrix and reduction of the stored energy associated with dislocations and subgrain boundaries [13,22,23].

The dynamic recrystallisation of metallic materials is classified into three types: discontinuous (DDRX), continuous (CDRX) and geometric (GDRX). DDRX usually occurs in highly pure Al and contains distinguishable nucleation and growth stages [12,24-27]. Grain bulging, dislocation rearrangement and boundary movement are the dominant mechanisms [28]. CDRX is the most commonly occurring mechanism observed in aluminium alloys under hot forming conditions, having been observed in alloys such as 7075 [21,29-31], 6082 [32,33], 7050 [34] and 5052 [35]. During this process, dislocations are continuously generated and rearranged to form subgrains bounded by low angle grain boundaries (LAGB, with misorientation of $2-15^{\circ}$ ). The whole microstructural evolution subsequently causes the creation of new grains surrounded by high angle grain boundaries (HAGB, with misorientation over $15^{\circ}$ ) [36]. GDRX usually occurs when grains are highly elongated, mainly due to large deformations. The applied strain is usually large enough that the original grains are thinned by grain migration to the extent that their width is near subgrain size, and original grain boundaries can connect, breaking up the elongated grains $[11,37]$.

Figure 1 presents a schematic illustration of the DDRX mechanism and an experimental example. Dislocations introduced by plastic deformation can glide and climb to form cell structures (subgrains) by dynamic recovery, as shown from images (1) to (2) in Figure 1a. These dislocation motions, as well as grain boundary sliding, can further promote boundary migration as a dominant and subgrain rotation as a secondary process. These migration and rotation processes trigger the nucleation of new grains; bulges containing no or few dislocations develop by migration of boundaries from the side with the lower dislocation density to the side with the higher density. These bulges are surrounded by accumulated dislocations, which form into subgrain boundaries. As the LAGB migrates and subgrains rotate, the bulges finally separate from the original grains to generate nuclei, creating a "necklace structure" in the early stages of DDRX, as illustrated in image (3) of Figure 1a. Nuclei form preferentially on or near grain boundaries (GB) and fine precipitates, which are high-energy sites that pin the movement of dislocations. In the later stages of deformation (i.e., growth stages) as shown in images (4) to (5) of Figure 1a, the nuclei grow continuously by the outward migration of boundaries, consuming the newly introduced dislocations until the original grains are completely replaced by finer recrystallised grains.

DDRX is usually observed in hot deformation of high-purity Al (99.999 wt\%+) [12,24-27]; an example is shown in Figure 1b. It is rarely reported in low-purity $\mathrm{Al}$, although DDRX phenomena have occasionally been observed in $\mathrm{Al}$ alloys such as 7050 and 7055 [34,38-40]. The occurrence of DDRX is attributed to the ability of extremely mobile GB to facilitate the nucleation and growth processes described above thanks to the lack of Zener drag.

Unlike for DDRX, the essence of CDRX is the continuous formation and rotation of subgrains created by dislocations, directly changing the orientation of subgrains and forming new grains $[32,33,41]$. 
As illustrated in Figure 2a, CDRX can be expressed in terms of cell structure formation in images (1) and (2), subgrain rotation (image 3), and conversion of grain boundaries from LAGB to HAGB (image 4), resulting in the final recrystallised grain microstructure seen in image (5). Subgrain rotation can increase the misorientation between adjacent subgrains such that their boundaries are classified as HAGB rather than LAGB. [29,31,35,42]. However, depending on the direction of the rotation of adjacent subgrains, such rotations could instead also result in subgrains with very similar orientations, which would then merge and be considered as a single grain. This phenomenon is annotated as "subgrain coalescence" in image (4) to (5) of Figure 2a [43,44]. CDRX usually begins along GB due to their high stored energy, especially where microshear bands form under a large localised strain [13].

(1) Original Coarse Grain

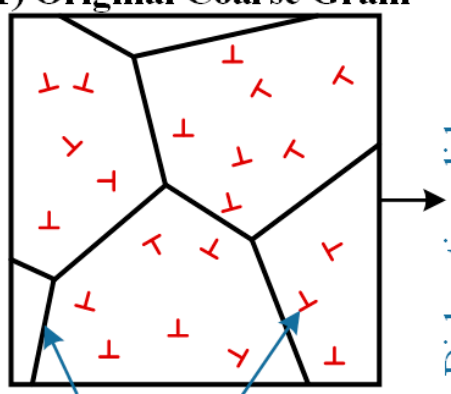

HAGB Dislocation

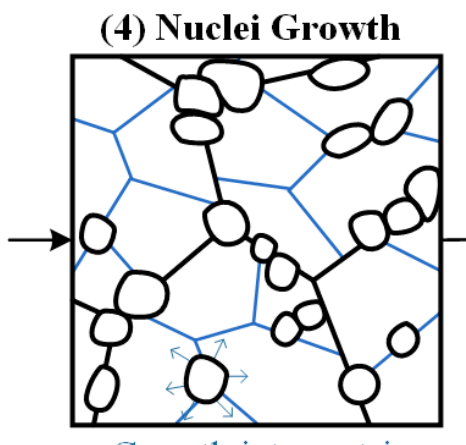

Growth into matrix
(2) Cell Structure

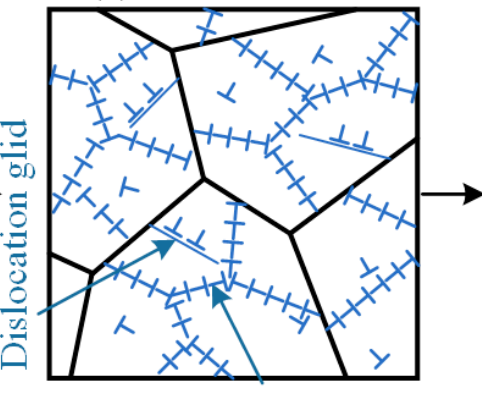

LAGB (dislocation climb)

\section{(5) Recrystallised Grain}



(a)

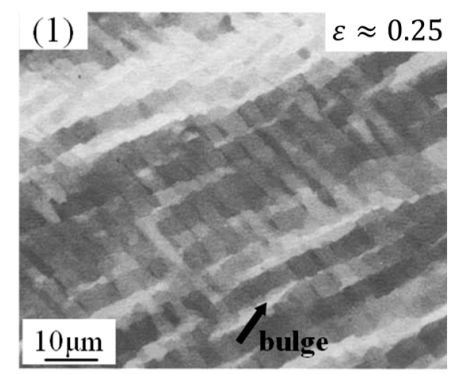

(b)

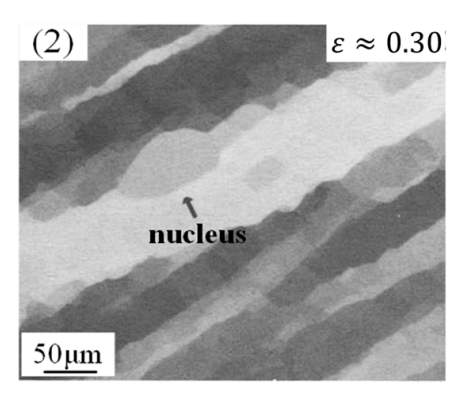

\section{(3) Nucleation}

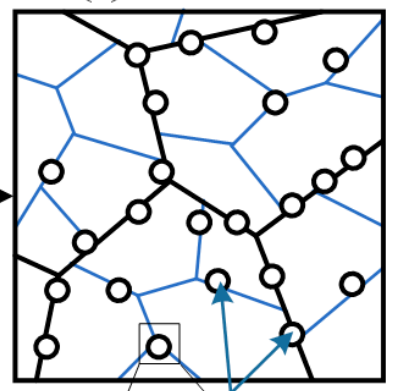

Nuqlei along GBs

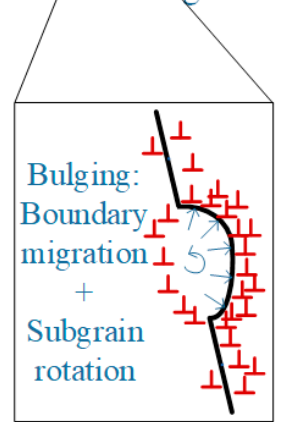

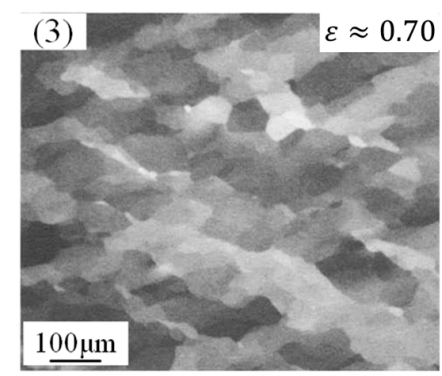

Figure 1. Development of new grains during DDRX: (a) schematic illustration, (b) experimental observation of as-annealed pure $\mathrm{Al}(99.999 \%)$ compressed at $350{ }^{\circ} \mathrm{C}$ and $1.11 \times 10^{-2} \mathrm{~s}^{-1}$ (Reproduced with permission from Elsevier [24]).

$\mathrm{CDRX}$ is the most common recrystallisation mechanism for both commercially pure $\mathrm{Al}$ and $\mathrm{Al}$ alloys under hot forming conditions. An example of this is given in Figure $2 b$, in which the numbers of the images correspond to the schematics in Figure 2a. CDRX is usually observed during tension, 
compression and torsion testing up to $0.7 T_{m}$, (where $T_{m}$ is the melting temperature) and has been seen under different strain rates from 0.0005 to $10 \mathrm{~s}^{-1}[32,33,35,45-47]$. CDRX has also been shown to exist, according to observations such as (i) a continuous increase in boundary misorientation with strain and (ii) recrystallised grains of smaller size than the original grains, in severe plastic deformation (SPD) processes, such as equal channel angular pressing (ECAP) [48,49], high pressure torsion (HPT) [50] and accumulative roll bonding (ARB) [14].
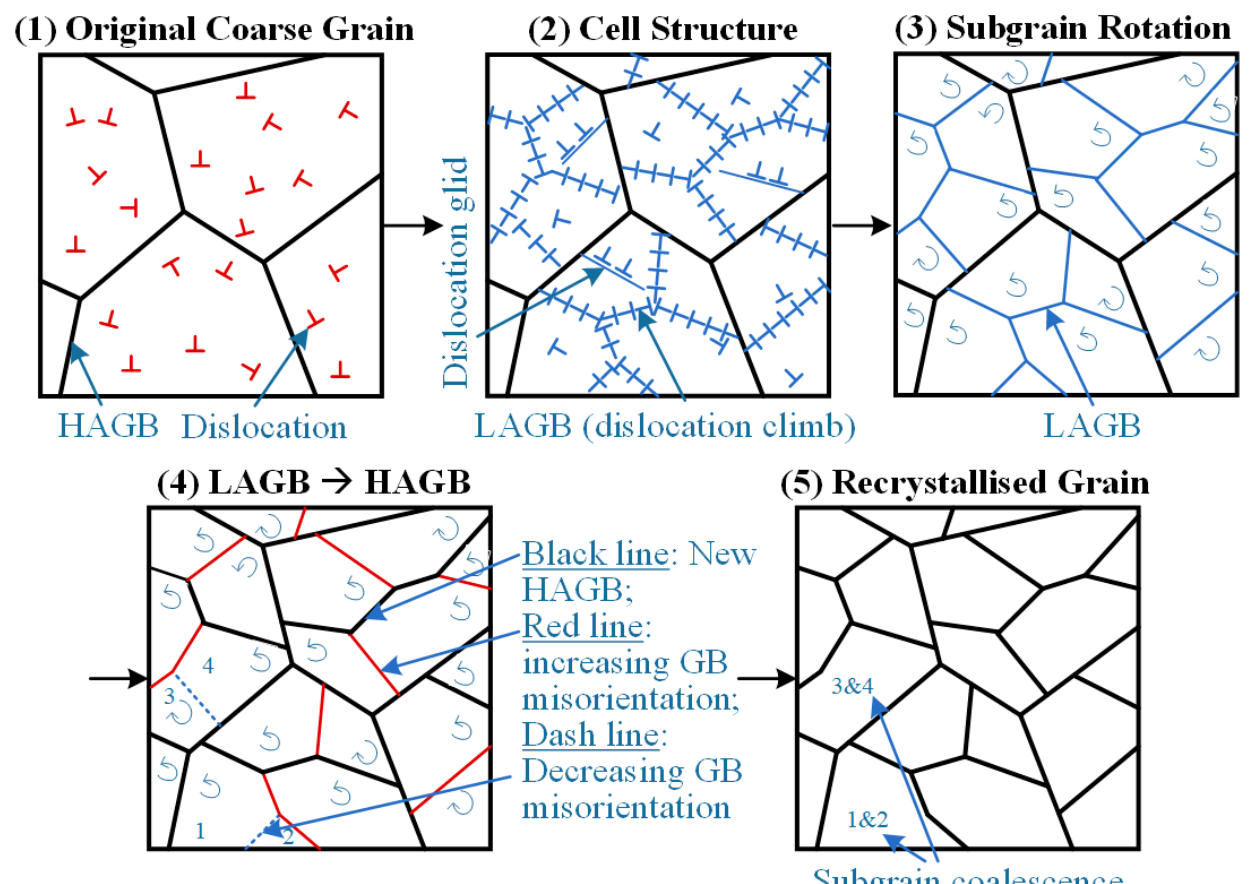

(a)
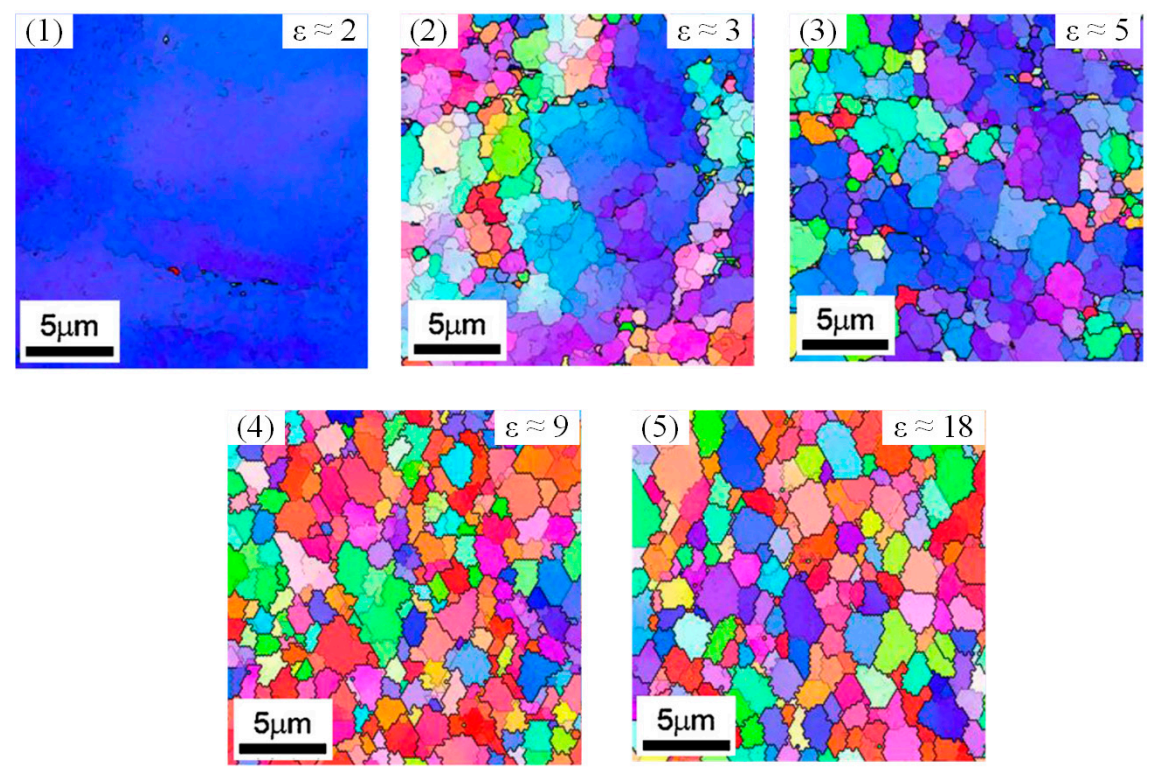

(b)

Figure 2. Development of new grains during CDRX: (a) schematic illustration, (b) experimental observation (EBSD IPF maps) of as-annealed pure $\mathrm{Al}$ (99.99\%) deformed by high-pressure torsion at room temperature (Reproduced with permission from Elsevier [42]). 
Figure 3 gives a schematic illustration of GDRX, in which the HAGB of original grains migrate and become serrated at junction points near LAGB and dislocation structures [51-53]. Encountering large strains, the original grains are continuously elongated until the transverse thickness decreases to around twice the typical subgrain size as illustrated in image (2) of Figure 3a. Subsequently, grains continue to be compressed, and the serrations on opposite sides meet each other, resulting in the fragmentation of old grains (pinch-off) and the generation of new grains as shown in image (3) of Figure 3a. During GDRX, the newly formed subgrains remain equiaxed and of constant size [54,55]. Observations of GDRX have been reported in $\mathrm{Al}$ alloys, especially during severe deformation processes; an example is given in Figure 3b [11,23,37,44,51,55-58]. However, GDRX has been neglected and is considered as a subtype of CDRX in most SPD-related literature [59].

(1) Original Coarse Grain (2) Grain Elongation



HAGB Dislocation

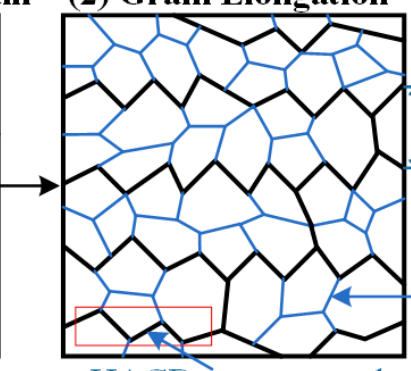

HAGBs are serrated

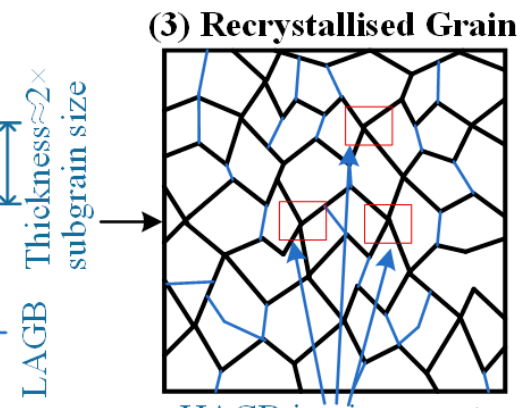

HAGB impingement

(a)
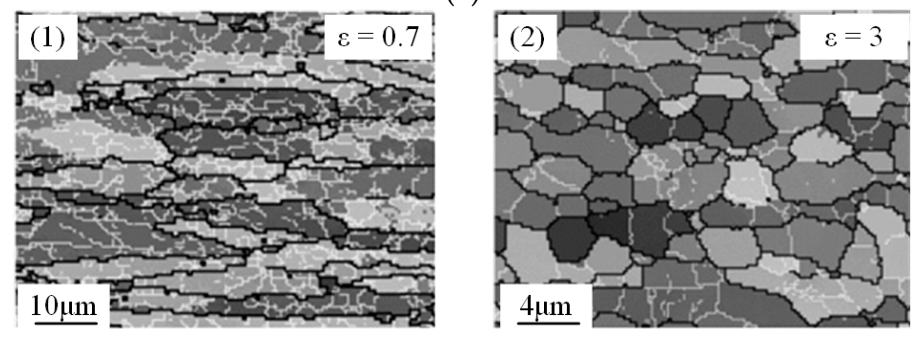

(b)

Figure 3. Development of new grains during GDRX: (a) schematic illustration, (b) experimental observation of as-annealed Al-3Mg-0.2Cr-0.2Fe alloy compressed at $350{ }^{\circ} \mathrm{C}$ and $0.1 \mathrm{~s}^{-1}$ (Reproduced with permission from Elsevier [55]).

The GDRX theory is still controversial and this type of dynamic recrystallisation is sometimes interpreted as CDRX since both feature a continuous increase in the area of HAGB and an absence of nuclei [56]. The key difference between CDRX and GDRX, however, is the evolution of the LAGB misorientations. During GDRX, these firstly increase and then plateau at a steady value, whereas during CDRX they continuously increase until they reach the threshold value at which the boundaries are considered to be HAGB $[58,60]$. The key difference between DDRX and GDRX is the shape of the original grains. Elongated original grains exist in GDRX, while the original grains remain in a relatively equiaxed shape in DDRX.

Figure 4 gives a compilation of dominant recrystallisation types under different conditions of forming temperature and strain rate. For as-fabricated $\mathrm{Al}$ alloys, $\mathrm{CDRX}$ and GDRX were reported, as summerised in Figure 4a. GDRX is more likely to occur during torsion processes with high temperature $\left(>400^{\circ} \mathrm{C}\right)$ and $\mathrm{CDRX}$ is more active from $300-400^{\circ} \mathrm{C}$, as indicated by the solid line. For quenched and naturally aged $\mathrm{Al}$ alloys, DDRX, CDRX and GDRX have all been observed, as shown in Figure 4b. GDRX is favourable at relatively high temperatures $\left(>475^{\circ} \mathrm{C}\right)$ for AA6082 and may also occur as a secondary mechanism, in conjunction with CDRX as the main mechanism, at $350-475^{\circ} \mathrm{C}$ with strain rate above $0.001 \mathrm{~s}^{-1}$. CDRX is dominant for most of the hot forming conditions at $\dot{\varepsilon} \geq 10^{-3} \mathrm{~s}^{-1}$, while a transition from CDRX to DDRX was reported when strain rates decreased below $10^{-3} \mathrm{~s}^{-1}$. DDRX is dominant at $350-450{ }^{\circ} \mathrm{C}$ with 
low strain rates of $5 \times 10^{-4} \mathrm{~s}^{-1}$. The boundary between CDRX and DDRX is still controversial, with some other research suggesting that decreasing temperature and increasing strain rate cause DDRX to prevail $[39,61]$. For aluminium alloys in as-homogenised and T6 conditions, Figure 4c, CDRX is the most active mechanism for all hot forming conditions. It should be noted that all the literature considered one or two dominant DRX types throughout the whole deformation process, hence an assumption is made here that strain level only affects the recrystallised fraction but not the DRX type.

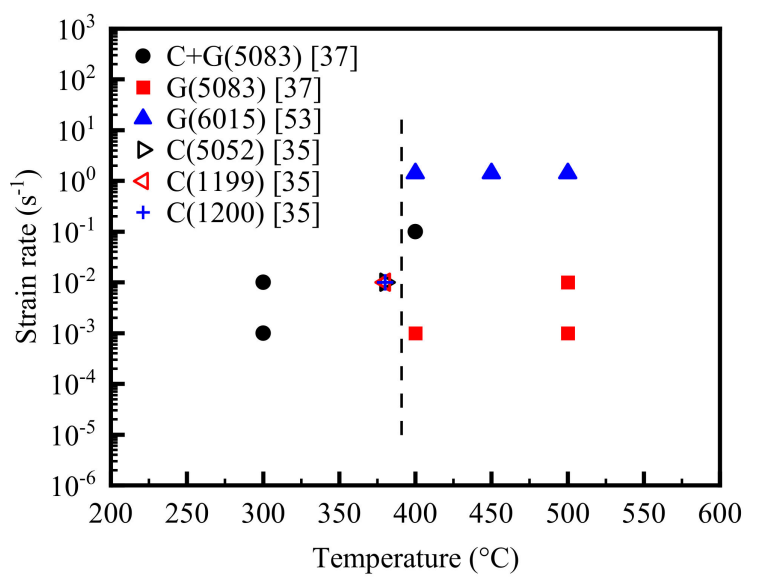

(a)

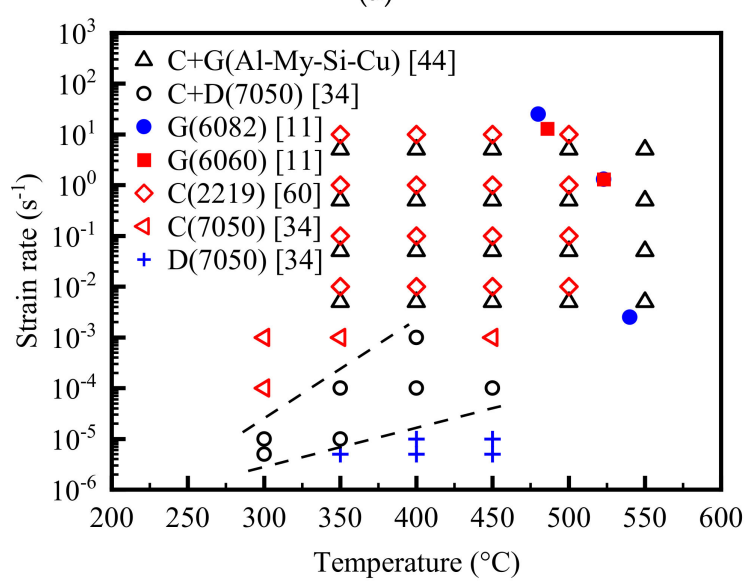

(b)

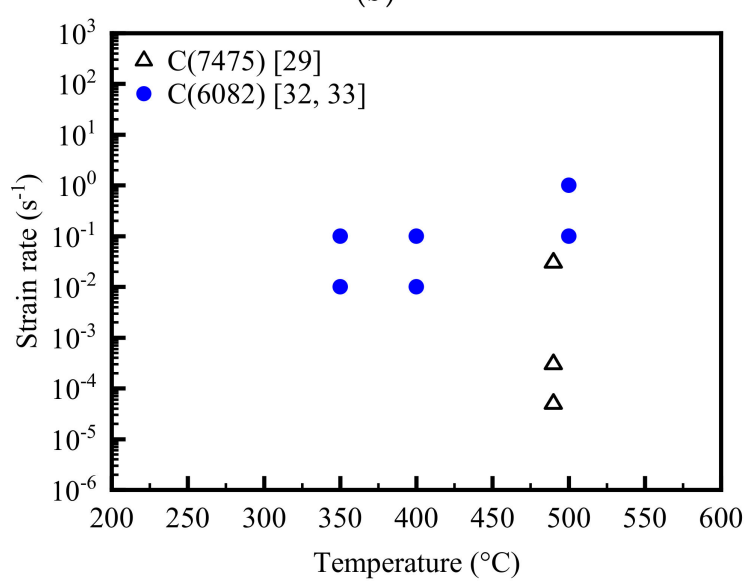

(c)

Figure 4. A summary of recrystallisation types under different thermomechanical conditions for (a) as-fabricated [35,37,53], (b) quenched and naturally aged [11,34,44,60], (c) as-homogenised 7xxx and T6-6xxx alloys [29,32,33]. Note: solid symbols represent torsion tests, while hollow and cross symbols represent compression tests. C, D and G represent CDRX, DDRX and GDRX respectively. 
The fundamental principles governing which recrystallisation type dominates are complex. In highly pure $\mathrm{Al}$, DDRX is preferred, whereas in $\mathrm{Al}$ alloys, which are high stacking fault energy (SFE) materials, CDRX is preferred because of the active dislocation recovery. In addition, GDRX is believed to occur due to extreme grain elongation during large deformation according to McQueen [51]. For example, during porthole extrusion, which separates the material into two parts and then welds them, GDRX was observed as a secondary mechanism in addition to the main mechanism of CDRX along the welding line where large monodirectional shear and compression are applied [62]. The different influencing factors compete with each other and the final result is the occurrence of one or two main recrystallisation mechanisms. The competing factors governing transformations among different recrystallisation types are the time needed for LAGB to transform into HAGB (CDRX) and the time necessary for original grain boundaries to migrate a sufficient distance for nucleation (DDRX) or elongation (GDRX) [63].

\subsection{Grain Growth Mechanism and Conditions of Occurrence}

Grain growth occurs during the whole hot deformation process and can continue after completion of recovery and recrystallisation to further reduce internal energy. The fundamental mechanism of grain growth is migration of HAGB along the direction perpendicular to the tangent plane of the grain boundary [64]. GB migration is a comprehensive result of various driving forces and drag forces. The main driving force for GB migration is the reduction of boundary energy through reduction of the boundary area. The capillarity effect also contributes to the migration. This mechanism plays an important role in shaping the whole GB network and determining which grains are more likely to be consumed by others [65]. Neglecting other factors, the capillarity effect will tend to make grain boundary angles close to an ideal value of $120^{\circ}$ [66]. In addition, GB tend to move towards grains with a higher dislocation density and thus more stored energy. The difference in subgrain size on either side of a GB also affects the GB migration. For the free surface of a metal sheet, the difference of surface tension should be considered as well $[67,68]$. The main drag forces that hinder grain growth are solute drag or Zener drag on GB from solute atoms, impurities and second-phase particles. The precipitation of various nanometre-size intermetallics plays a crucial role in controlling the microstructural stability of aluminium alloys [69].

Grain growth can be normal (continuous) or abnormal (discontinuous), corresponding to a uniform or heterogeneous increase in grain size, as shown in Figure 5. The evidence of abnormal grain growth is the sudden appearance of one or more extremely large grains surrounded by much smaller grains, leading to two distinctly different grain populations: fine-grained matrix and coarse-grained matrix. Localised destabilisation must occur to satisfy the conditions for abnormal growth. If there are clusters of grains with nearly the same orientations, a large grain can form by the decomposition of grain boundaries due to grain rotation. Abnormal grain growth can also take place in particle-depleted regions in materials where grain growth is governed only by the pinning of GB by particles [69-71].

For most engineering problems, evolution of average grain size is the key parameter for characterising normal grain growth. Figure 6 summarises the typical relationship of mean grain size with time and temperature for various $\mathrm{Al}$ alloys during normal grain growth. The grain size-time curves indicate that grains grow with time and the growth rate decreases continuously. Higher temperatures favour faster grain growth. The grain size-temperature curves show an overall thermal sensitivity of metal instability (grain growth). Al alloys tend to remain stable against grain growth below a critical temperature and exhibit rapid grain growth above this value. Although many factors including material composition [72], processing methods [73] and microstructures [74] can change this critical temperature, Figure $6 \mathrm{~b}$ is able to show a general domain in which alloys are likely to be stable against grain growth. $5 \mathrm{xxx}$ series $\mathrm{Al}$ alloys have a relatively low critical temperature range of $150-200^{\circ} \mathrm{C}$. The critical temperature of $2 x x x$ alloys is around $200^{\circ} \mathrm{C}$. Pure aluminium has a critical temperature for grain growth from 200 to $250^{\circ} \mathrm{C}$. Al-Zr alloys become unstable when subjected to 
annealing over $250^{\circ} \mathrm{C}$. Al alloyed with $\mathrm{Zn}(7 x x x)$ or Sc as additive elements have been shown to be thermally stable even at high temperatures up to $400{ }^{\circ} \mathrm{C}$.

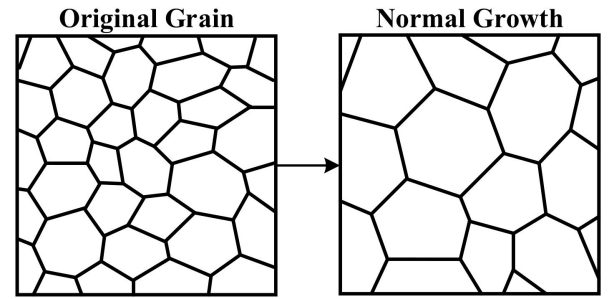

(a)



(c)

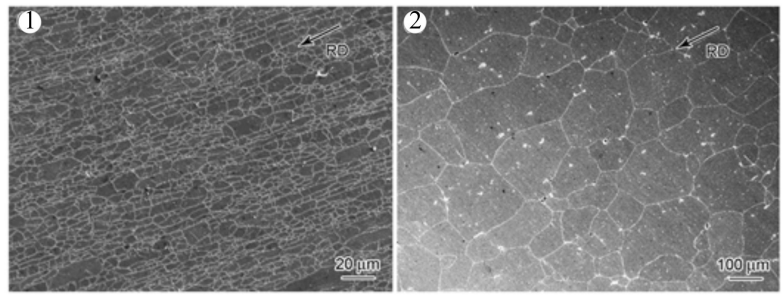

(b)

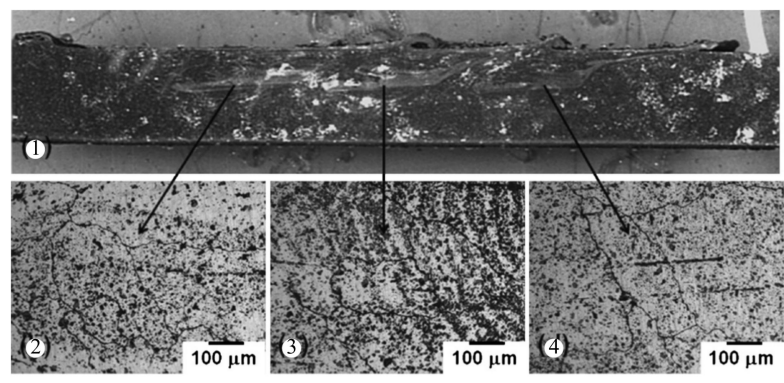

(d)

Figure 5. Grain growth of aluminium alloys. (a) Schematic and (b) corresponding experimental observation for normal grain growth. The experimental observation is of as-extruded AA7055 before (left) and after (right) annealing at $520{ }^{\circ} \mathrm{C}$ for $90 \mathrm{~min}$ (Reproduced with permission from Springer Nature [70]); (c) Schematic and (d) corresponding experimental observation for abnormal grain growth. The experimental observation is of friction stir processed Al-7Si-0.6 Mg alloy (Reproduced with permission from Elsevier [71]).



(a)



(b)

Figure 6. Grain size evolutions (a) with time for ECAP-processed Al0.1Sc alloy annealed at various temperatures [74] and (b) with temperature for different $\mathrm{Al}$ alloys after $1 \mathrm{~h}$ annealing [69,72-79]. 


\section{Macroscopic Response of Microstructures during and after Hot Forming}

\subsection{Effects of Microstructures on Viscoplastic Behaviour during Deformation}

\subsubsection{Microstructural Evolution during Hot Deformation}

The dislocation density evolutions during hot deformation are shown schematically in Figure 7. New dislocations are generated from existing ones by multiplication processes, and these new dislocations then move to relieve localised stress during deformation [80-82]. Mobile dislocations give rise to the inelastic stress flow and immobile dislocations play a hardening role in the viscoplastic behaviour of aluminium alloys. When no recrystallisation occurs, the dislocation density increases in the early stages of deformation, becoming saturated at the later stages due to recovery [83-85], as shown in Figure 7a. Higher temperatures and lower strain rates facilitate thermally activated recovery and hence reduce the density of dislocations. When recrystallisation occurs, work hardening, recovery and recrystallisation compete to determine the evolution of the dislocation substructure [86]. The dislocation density first rises when work hardening and recovery prevail, then decreases to a steady state value when recrystallisation becomes dominant, consuming dislocations by grain boundary migration and subgrain rotation as shown in Figure $7 \mathrm{~b}$ [87]. Higher temperatures and/or lower strain rates promote both recrystallisation and recovery, hence reducing the dislocation density [88,89].

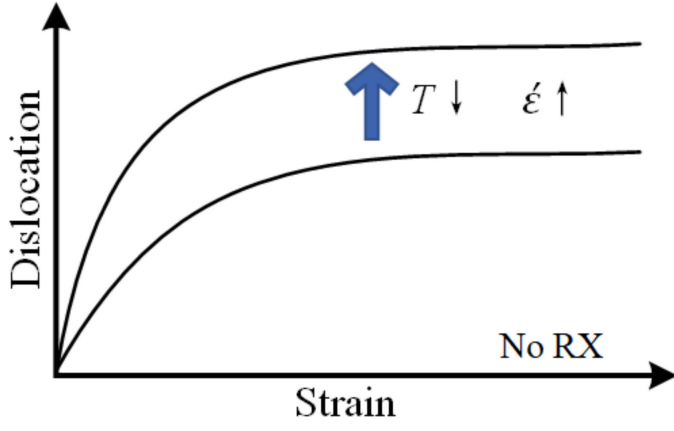

(a)

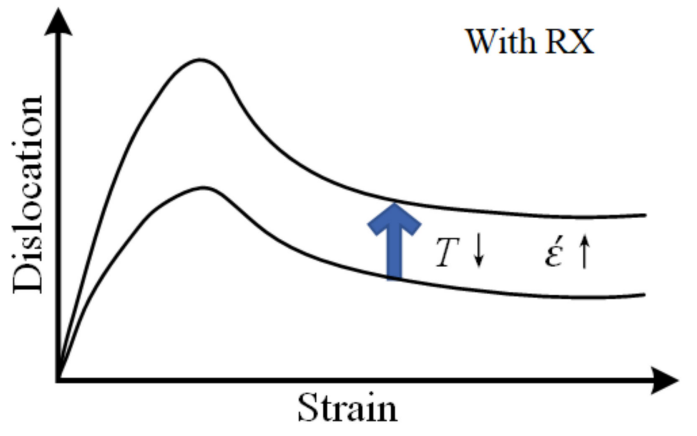

(b)

Figure 7. Schematic illustration of dislocation density evolution during deformation with (a) no recrystallisation and $(\mathbf{b})$ recrystallisation.

Figure 8 is a schematic illustration of the evolutions of (a) LAGB area and (b) HAGB area as a function of strain. In Figure 8a, the area of LAGB initially increases continuously with increasing strain because of the dynamic rearrangement of dislocations, then saturates at later stages of deformation due to the replacement of LAGB by HAGB during recrystallisation [36]. Lower temperatures and higher strain rates increase the rate of dislocation generation and reduce the rate of dislocation annihilation, resulting in more LAGB [90]. Figure $8 b$ is the corresponding schematic plot for the HAGB area. The boundary area of a grain increases when it is transformed from an equiaxed (approximately spherical) shape to one of elongated (approximately elliptical) shape during plastic deformation [91]. When dynamic recrystallisation occurs, the nucleation of grains in DDRX, continuous transformation from LAGB to HAGB during CDRX and the grain pinch-off during GDRX cause further increases in the area of HAGB. Higher temperatures and lower strain rates decrease the HAGB area by facilitating grain growth (associated with a decrease in grain boundary area) over DRX and grain elongation.

Figure 9 illustrates the general evolution of LAGB and HAGB misorientations during the hot deformation process. The average LAGB misorientation increases up to $2-3^{\circ}$ at strains of $\sim 1$ during work hardening and 3-8 $8^{\circ}$ during recrystallisation, as shown in Figure 9a [92-94]. For GDRX, the average LAGB of $3-8^{\circ}$ can be separated into two populations: about $1 / 3$ of the LAGB finally reach $15^{\circ}$ and $2 / 3$ LAGB saturate at $5^{\circ}$ as shown in Figure $9 b[54,56,58]$. The dependence of LAGB misorientation 
on temperature and strain rate is still not well understood, since the opposite effects on LAGB misorientation evolution have also been observed [94]. The original HAGB misorientation stays nearly constant without recrystallisation, as shown in Figure 9c. New HAGB can only form during recrystallisation with continuous increase of misorientation. An incubation strain (about 1-2) was observed within which some of the LAGB underwent a dramatic increase in misorientation to the extent that they transformed into HAGB $[21,35,59]$. The effect of temperature on the average misorientation is not the same in all $\mathrm{Al}$ alloys. For example, AA7475 shows an increasing average misorientation with temperature while the inverse is true with AA2219 [21,48,95]. It is supposed that the GB misorientation increases with the increasing temperature below a critical temperature but decreases once the temperature exceeds this value.

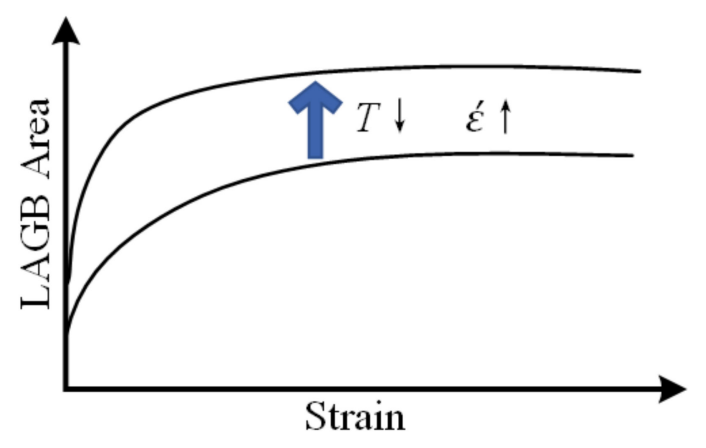

(a)

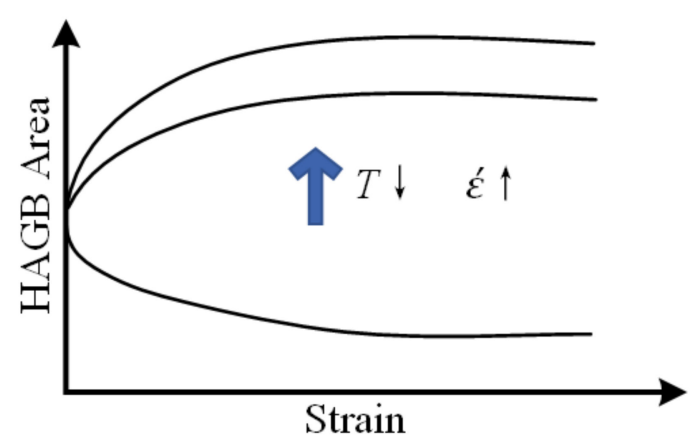

(b)

Figure 8. Schematic illustration of changes in boundary area with strain: (a) LAGB area evolution and (b) HAGB area evolution per unit volume, which have similar trends but different mechanisms depending on whether or not recrystallisation occurs.

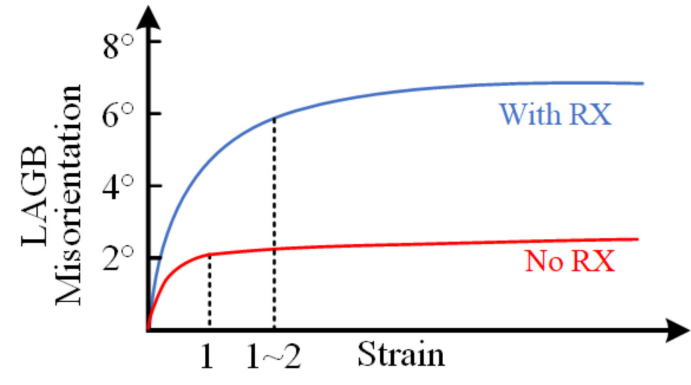

(a)



(b)

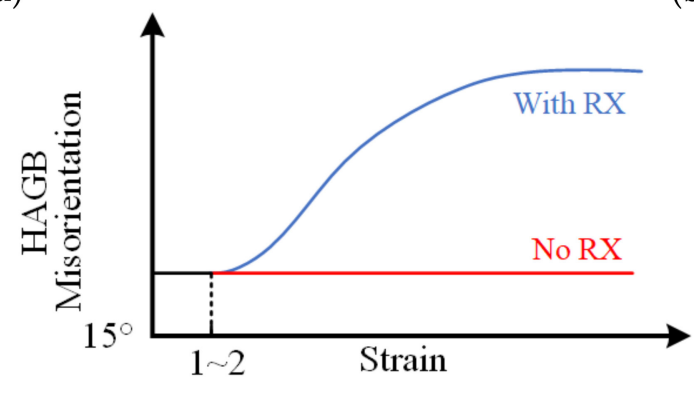

(c)

Figure 9. Schematic illustration of (a) LAGB misorientation evolution with or without DRX, (b) detailed LAGB misorientation evolution in GDRX and (c) HAGB misorientation evolution with or without DRX.

Figure 10 illustrates the evolution of grain size with the increasing strain. Individual grains can expand outward at the expense of the adjacent grains; those grains that become smaller during 
this process tend to disappear, resulting in an increase in grain size without recrystallisation. By contrast, increasing the number of grains via recrystallisation gives a reduction in average grain size. The competition of grain growth and recrystallisation determines the overall evolution of grain size, as shown in Figure 10. A steady-state grain size is eventually achieved, which is higher for higher temperatures and lower strain rates [96,97].



Figure 10. Schematic illustration of the evolution of grain size with strain.

\subsubsection{Microstructural Evolution during Hot Deformation}

Figure 11 schematically illustrates the viscoplastic behaviour with possible associated mechanisms. The flow stress increases dramatically during the cold working process when the dislocation density dramatically increases and interactions between dislocations reduce their mobility, as shown in curve (1) of Figure 11. At elevated temperatures that are still below the recrystallisation temperature, the flow stress increases monotonically until saturation due to active dynamic recovery, as shown in curve (2) [98-100]. At a deformation temperature higher than the recrystallisation temperature, the flow stress will fall after a peak value, then stabilise at a lower value, as shown in curves (3) and (4) in Figure 11.

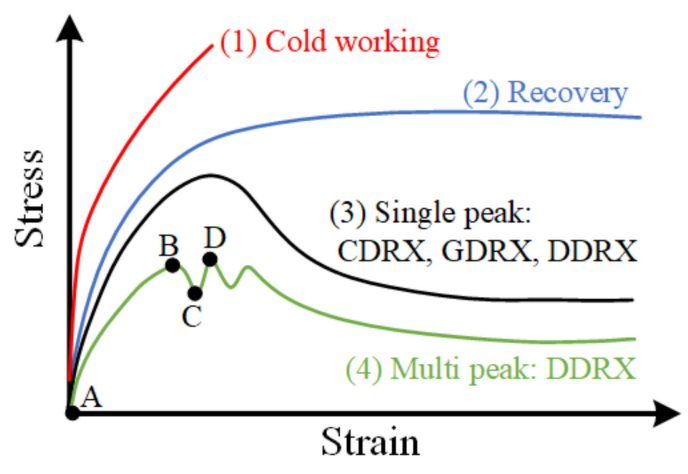

Figure 11. Schematic illustration of the flow stress behaviour with different mechanisms.

For recrystallisation in aluminium, two different kinds of stress-strain curves may be observed according to the type of recrystallisation. During DDRX, the stress increases smoothly from point A to B in curve (4) of Figure 11; during this segment, work-hardening dominates over the concurrent dynamic recovery. The stress subsequently shows fluctuations around the peak as shown by the path from points $\mathrm{B}$ to $\mathrm{D}$, because of the competition of dislocation accumulation during work-hardening and annihilation during recovery and nucleation $[12,24,25,27]$. From point $B$ to $C$, recrystallisation takes place, softening the material by reducing the dislocation density. From point $C$ to $D$, the remaining dislocation density is insufficient for further nucleation and growth of grains, hence dislocations accumulate, resulting in an increase in the flow stress. Several such oscillations in flow stress may occur before a final decrease towards a steady state. During CDRX or GDRX, the stress increases monotonically up to a peak value 
and then decreases into a steady state, as shown in curve (3) [29,31,33,42,44]. Higher temperatures and lower strain rates accelerate the recovery, giving rise to lower stresses both at the peak and in the steady state [98].

The relationship among microstructural variables, hot deformation conditions and viscoplastic behaviour is schematically summarised in Figure 12. Dislocations are generated and move by slip giving rise to plastic deformation; they are consumed by subgrain rotation and boundary migration. These subgrain rotation and boundary migration processes are the fundamental mechanisms of recovery, recrystallisation, and grain growth, which change the grain size and misorientation. Subgrain rotation causes an increase in grain misorientation and a transformation from LAGB to HAGB, while boundary migration causes a reduction in the area of LAGB and HAGB. The externally applied conditions (i.e., T, $\varepsilon, \dot{\varepsilon}$ ) affect the viscoplastic behaviour by triggering the deformation mechanism and causing continuous evolution in deformation-related microstructures (i.e., dislocation densities, grain size, HAGB, LAGB and misorientations).

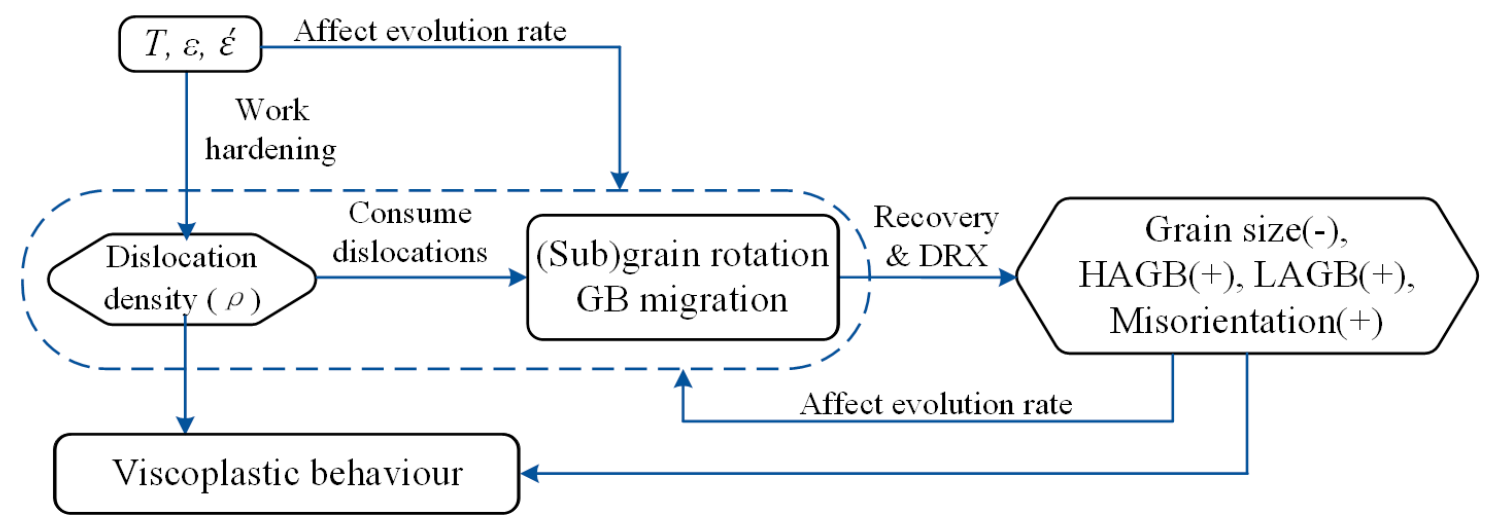

Figure 12. Relationship between external parameters and microstructural variables.

\subsection{Effects of Microstructures on the Post-Forming Mechanical Properties}

\subsubsection{Tensile Properties}

The dependence of yield strength on grain size for Al alloys satisfies the Hall-Petch law, i.e., $\sigma_{y}=\sigma_{0}+\frac{k_{y}}{\sqrt{d}}$, where $\sigma_{y}$ indicates the yield strength, $\sigma_{0}$ is the friction stress for dislocation movement, $d$ is the average grain size and $k_{y}$ is a strengthening coefficient related to parameters such as alloy content, boundary misorientation and dislocation density [15,101]. Figure 13 summarises the relationship between material yield strength and grain size for both pure Al and its alloys. All curves show good linear correlations between $\sigma_{y}$ and $d^{-1 / 2}$. In some other metallic materials such as $\mathrm{Cu}$ and steels, it has been found that the value of $k_{y}$ became negative below a grain size of $\sim 10 \mathrm{~nm}$. However, $k_{y}$ is always positive for $\mathrm{Al}$, i.e., the smaller the grain size, the higher the yield strength, according to the existing experimental results. The Hall-Petch relationship in Al indicates that the sensitivity of the yield strength to the grain size decreases with the increasing grain size. This means that in coarse-grained materials such as cast $\mathrm{Al}$, a change in the grain size will not give much change in yield strength.

Figure $14 \mathrm{a}, \mathrm{b}$ shows the dependence of material elongation on grain size. Normalised uniform elongation (elongation at the maximum load) is used for evaluating the ductility with different grain sizes; this is obtained by dividing by the highest uniform elongation value measured for each material type such that the resulting values fall between 0 and 1 . As seen from the summarised data in Figure $14 \mathrm{a}$, the normalised elongation dramatically increases when the grain size is smaller than $10 \mu$ m. However, when the grain size exceeds $10 \mu \mathrm{m}$, as shown in Figure 14b, an apparent reduction in the normalised elongation is observed. This trend is schematically illustrated in Figure 14c, where the normalised elongation is divided into three stages. In the low-elongation stage, uniform elongation remains stable until the grain size increases to a critical value (ranging from $0.4-2 \mu \mathrm{m}$ ), at which point the uniform elongation abruptly increases. This critical size is believed to be determined by the dislocation cell size. 
Grains smaller than this criterion are too small to enable dislocation movement, thus leading to low uniform elongation. With grains larger than this criterion, dislocations can move freely and hence the elongation is increased. For the second stage, the dislocation mobility saturates and no significant effect of grain size on ductility is observed. When the grain size is larger than the value of $t / c$, where $t$ indicates the specimen thickness, and $c$ is a constant about 4-5, elongation decreases with the increasing grain size. During this stage, the increasingly obvious anisotropy of the coarse-grained metal results in inhomogeneous plastic deformation, facilitating necking and reducing the uniform elongation.

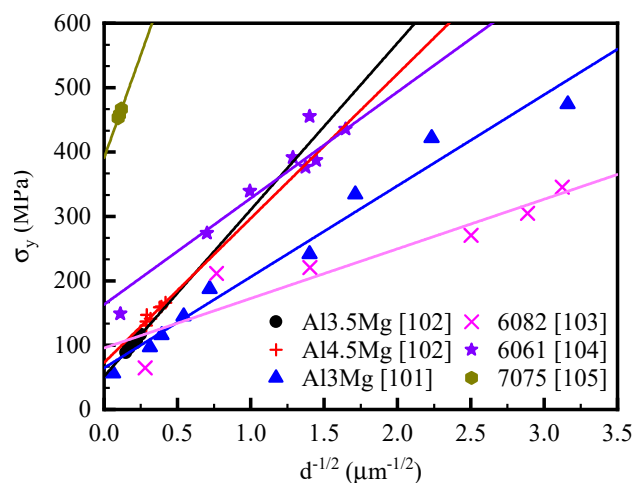

(a)

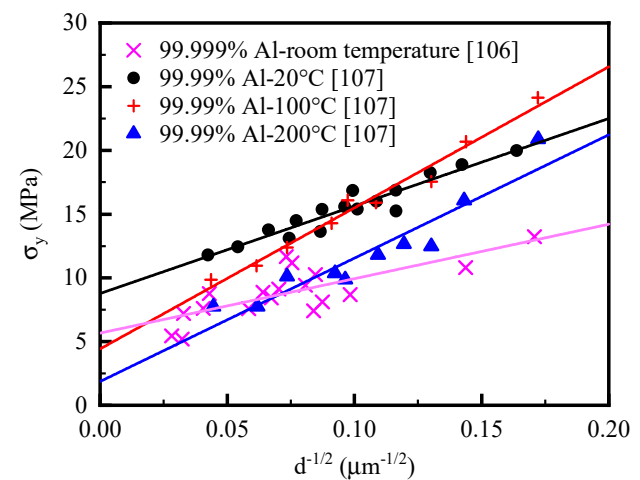

(b)

Figure 13. Relationship between yield strength $\left(\sigma_{y}\right)$ and $d^{-1 / 2}$ for (a) Al alloys at room temperature [101-105] and $(\mathbf{b})$ pure $\mathrm{Al}$ at different temperatures [106,107]. Here $d$ is the average grain size.

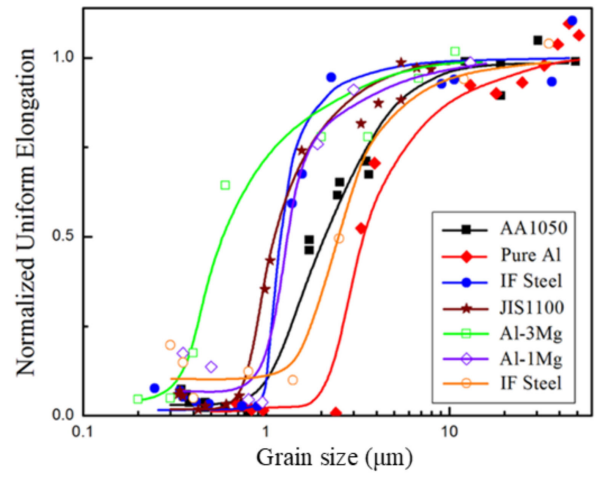

(a)

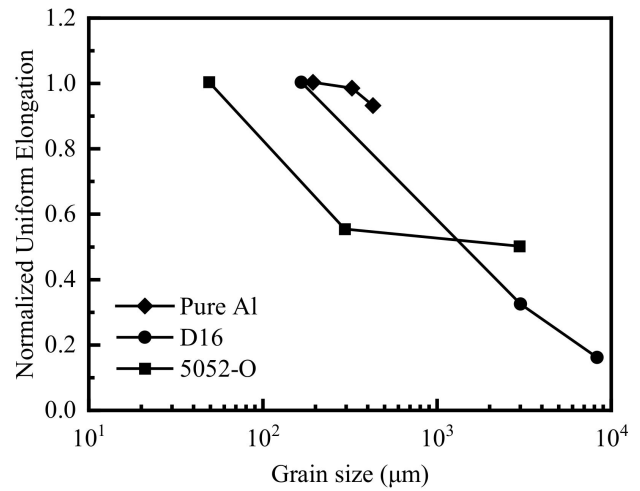

(b)



(c)

Figure 14. Grain size dependence of uniform elongation in (a) ultrafine and medium grain size range $(<100 \mu \mathrm{m})$; (b) coarse grain range $(>100 \mu \mathrm{m}$, redrawn from source reference) and (c) schematic illustration for grain size-dependent uniform elongation, where $t$ indicates the specimen thickness, and $c$ is a constant with a value of about 4-5 (Reproduced with permission from Springer Nature [108]). 


\subsubsection{Fatigue Properties}

Fatigue properties include crack nucleation, short crack propagation, and final rapid failure [109]. The fatigue properties of aluminium components are strongly related to the dislocations and their interactions with both GB and surfaces [110]. The irreversible to-and-fro dislocation motion due to cyclic loads leads to detectable microstructural features such as slip bands and dislocation dipoles. This piling-up of dislocations intensifies over and over, finally resulting in the nucleation of cracks [109]. GB are stress concentration sites where cracks are highly likely to initiate. Cracks can subsequently propagate on further loading but can concurrently be hindered by GB, especially when the angle between the crack and GB directions is around $90^{\circ}$ [111]. GB can also alter the crack propagation direction and increase the multiplicity of cracking directions, which enhances the dynamic damage tolerance [112]. In contrast to this, GB can accelerate crack propagation by acting as the best and fastest crack path when a crack tip connects to a cracking GB $[113,114]$. It can be seen that the effects of GB on the fatigue resistance depend on detailed circumstances and should be evaluated comprehensively. In the high-cycle fatigue regime, where crack nucleation predominates for most of the fatigue life, grain refinement can greatly improve the initiation life, although it promotes crack propagation afterwards [111]. In low-cycle fatigue regimes where the applied stress is high, grain size is observed to have a limited effect on fatigue properties.

Figure 15 shows the fatigue properties with respect to grain size. As can be seen, increasing the grain size reduces the number of cycles to failure, i.e., grain refinement can enhance failure resistance for AA7050 and pure Al $[115,116]$. However, the curves of crack propagation rate against grain size for AA2524 show that increasing the grain size reduces the crack propagation rate especially with grains of the order of $100 \mu \mathrm{m}$, i.e., grain refinement can weaken failure resistance for AA2524 [117,118]. It should be noted that the effect of grain size on fatigue properties is especially pronounced with a grain size of around $150 \mu \mathrm{m}$, according to Figure 15.



Figure 15. Solid lines: relationship between number of cycles to failure and grain size of welded AA7050 rolled plates under bending fatigue test [115], and as-annealed pure Al under uniaxial fatigue test at room temperature with a stress amplitude of $100 \mathrm{MPa}$ [116]; dashed lines: relationship between crack propagation rate and grain size of T3-treated AA2524 [117] and solutionised and aged AA2524 at room temperature and stress ratio of 0.1 with loading frequency of $10 \mathrm{~Hz}$ [118].

\section{Material Modelling of Recrystallisation and Associated Viscoplastic Behaviour}

Modelling methods can be divided into four types, as illustrated in Figure 16:

(1) Empirical and semi-empirical models characterise the stress-strain relations as functions of macroscopic quantities including temperature, strain rate and strain using a phenomenological approach. Equations are established based on the analysis of large numbers of experimental 
results. This type of model can give good agreement with test results but does not capture microstructural evolution.

(2) Dislocation-based models describe all microstructural evolutions and macroscopic mechanical responses in terms of functions of dislocation density. This approach provides a fundamental microscopic view of metallic materials during hot deformation, considering complex dislocation structures.

(3) Semi-dislocation-based models treat dislocations and grain boundaries as separate microstructural entities. The expression of dislocation density is similar to the unified dislocation-based model in (2).

(4) Physically based models emphasise the intricate interactions among various microstructural variables including dislocation density, grain size, recrystallised fraction, grain misorientation and boundary migration mobility. This approach models all the microstructural evolutions considered and their effect on viscoplastic properties.

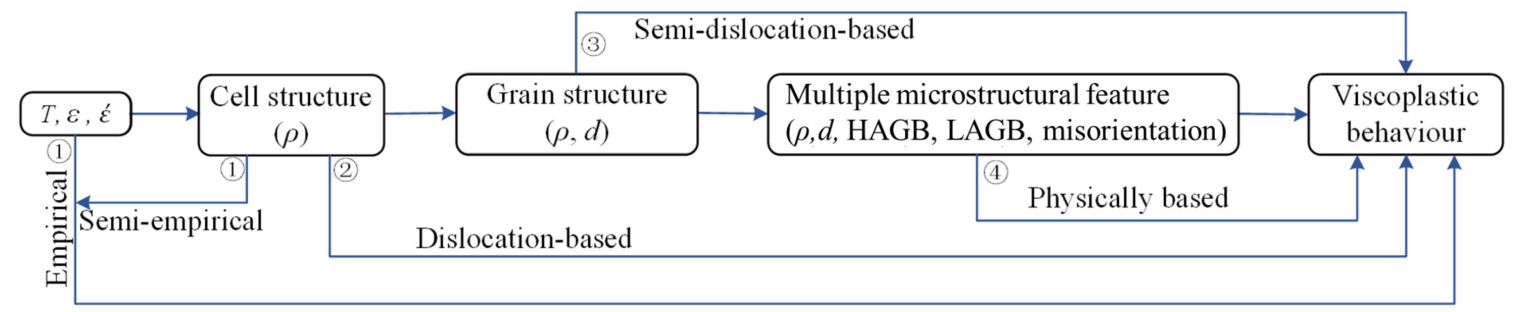

Figure 16. Description of different types of modelling methods.

It should be noted that the meaning of each parameter in the following equations is listed in the nomenclature section at the beginning of this paper. Common variables that appear repeatedly are especially explained here: $\sigma$-stress, $\varepsilon$-strain, $\dot{\varepsilon}$-strain rate, $\varepsilon_{p}$-plastic strain, $\dot{\varepsilon}_{p}$-plastic strain rate, $\tau$-shear stress, $\gamma$-shear strain, $\dot{\gamma}$-shear strain rate, $T$-temperature, $\rho$-dislocation density, $M$-dislocation mobility, $G$-shear modulus, $b$-Burgers vector, $\theta_{\text {dis }}$-misorientation, $d$-grain size.

\subsection{Empirical and Semi-Empirical Models}

The first phenomenological model was presented by Andrade et al. in 1914 to describe the deformation-time relation of metal under constant loading, using a power or exponential function [119]. Later, the Norton-Hoff model was proposed, which simply contains one dashpot to express the stress-strain relationship without considering elasticity; this was later developed into the Bingham-Norton model to better describe the observed viscoplastic behaviour of materials [120]. Johnson and Cook established a widely used model in 1983 to link flow stress to plastic strain considering the effects of temperature and strain rate, as shown in Equation (1) [121], where $A^{*}, B^{*}, C^{*}$ $m_{1}, m_{2}$ and $\dot{\varepsilon}_{0}$ are constants. Zerilli $[122,123]$ later proposed Equation (2) to describe the stress-strain behaviour of FCC metals, including aluminium. Further improvements have been made to optimise the form of the equation and methods of parameter determination, such as modifying originally constant parameters into expressions in terms of strain rate [124].

$$
\begin{gathered}
\sigma=\left(A^{*}+B^{*} \varepsilon^{m_{2}}\right)\left[1+C^{*} \ln \left(\frac{\dot{\varepsilon}}{\dot{\varepsilon}_{0}}\right)\right]\left(1-T^{m_{1}}\right), \\
\sigma=A^{*} \varepsilon^{0.5} \exp \left(-B^{*} T+C^{*} T \ln \dot{\varepsilon}\right) .
\end{gathered}
$$

Researchers have also tried to find the physical basis of these formulae. For example, Equation (3) presents the classical relationship between stress and dislocation density [83] and Equation (4) describes the evolution of dislocation density during work hardening and recovery [125]. The combination of 
Equations (3) and (4) yields the viscoplastic flow, as given in Equation (5) [126]. Adding the influence of recrystallisation yields the modelling equation in Equation (6) [127],

$$
\begin{gathered}
\sigma=\alpha M G b \sqrt{\rho}, \\
\rho=\frac{U}{\Omega}-\left(\frac{U}{\Omega}-\rho_{0}\right) \exp \left(-\Omega \varepsilon_{p}\right), \\
\sigma=\sqrt{\left[\sigma_{D R V}^{2}+\left(\sigma_{0}^{2}-\sigma_{D R V}^{2}\right) \exp \left(-\Omega \varepsilon_{p}\right)\right]} \\
\sigma=\sigma_{D R V}-\left(\sigma_{p e}-\sigma_{s s}\right)\left\{1-\exp \left(-K_{d}\left(\frac{\varepsilon_{p}-\varepsilon_{c}}{\varepsilon_{p e}}\right)^{n_{d}}\right)\right\},
\end{gathered}
$$

where $\alpha, U, \Omega, K_{d}, n_{d}$ are material constants. $U$ corresponds to hardening and $\Omega$ denotes dynamic recovery. $\sigma_{0}$ and $\sigma_{D R V}$ indicate the yield stress and steady-state stress due to recovery, respectively. $\sigma_{p e}$ and $\sigma_{s s}$ indicate the peak stress and steady-state stress due to recrystallisation, respectively. $\varepsilon_{\mathcal{c}}$ is the critical strain for the occurrence of dynamic recrystallisation, and $\varepsilon_{p e}$ is the peak strain. $\sigma_{0}, \sigma_{D R V}$, $\sigma_{p}$ and $\sigma_{s s}$ are all considered as parameters dependent on $T$ and $\dot{\varepsilon}$, regardless of dislocation effects. These models are considered to be semi-empirical, as they do not provide a detailed description of the microstructural evolution even though they are derived on the basis of dislocation evolution.

An example that shows the comparison of an empirical model with experimental stress-strain curves is illustrated in Figure 17 [128]. Figure 17a shows the effect of strain rate on the stress-strain curves while Figure 17b shows the effect of temperature. By fitting the viscoplastic behaviour using suitable material constants, excellent agreement could be achieved between the experimental and predicted stress-strain curves within the temperature and strain rate ranges studied. However, such modelling methods are not able to describe any microstructural behaviour. Therefore, although the models may predict the deformation behaviour of the material well, they are not able to output the microstructural evolutions, which are important for assessing the mechanical properties after forming. 


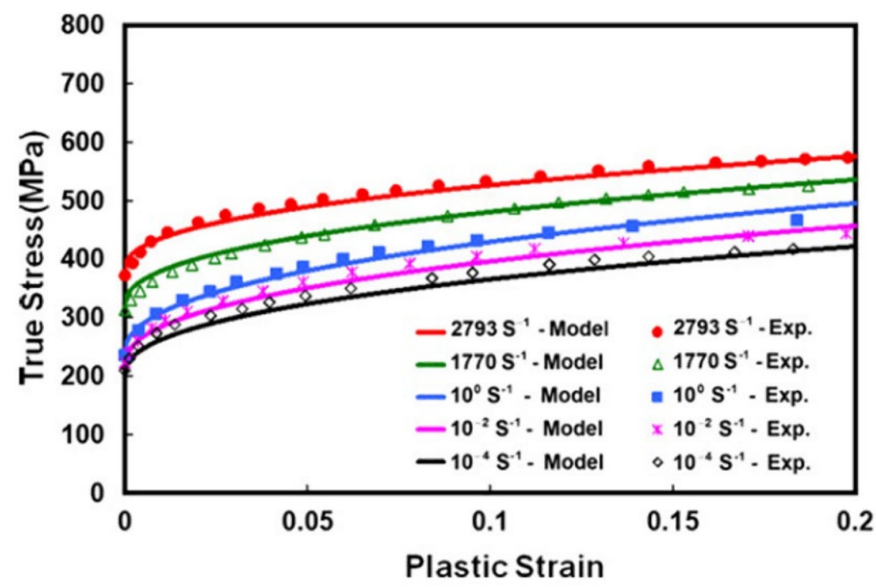

(a)

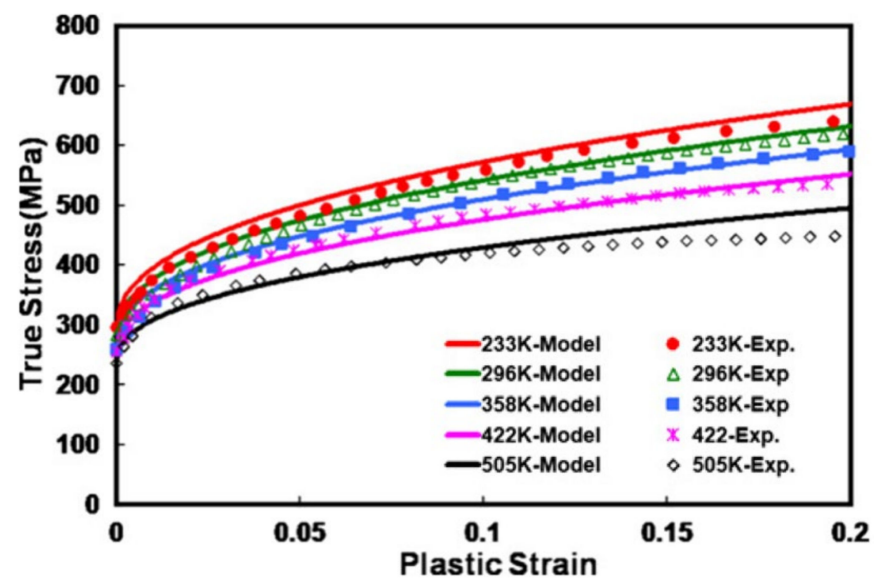

(b)

Figure 17. Experimental (symbols) and computed (solid lines) stress-strain curves of AA2024-T351 from uniaxial compression tests at (a) a temperature of $232{ }^{\circ} \mathrm{C}$ with different strain rates, and (b) a strain rate of $10 \mathrm{~s}^{-1}$ at different temperatures (Reproduced with permission from Elsevier [128]).

\subsection{Dislocation-Based Models}

The first dislocation-based model was proposed by Estrin et al. [83] for modelling the hardening behaviour of copper in deformations with large strains considering the evolution of dislocation density. The model separates cellular dislocation structures into two phases corresponding to cell walls, $\rho_{\mathcal{C}}$, and cell interiors, $\rho_{w}[16,83,129-131]$. The rate of change of cell interior dislocation density $\dot{\rho}_{c}$ is described in Equation (7), where the first term represents the generation of cell interior dislocations by absorption of the cell wall dislocations, and the second and third term describes their annihilation due to recovery. The rate of change in the density of cell wall dislocations, $\dot{\rho}_{w}$, is given in Equation (8).

$$
\begin{aligned}
& \dot{\rho}_{c}=\alpha^{*} \frac{2}{3 \sqrt{3}} \frac{\sqrt{\rho_{w}}}{b} \dot{\gamma}_{w}-\beta^{*} \frac{4 \dot{\gamma}_{c}}{b d_{c} \sqrt{1-f}}-k_{0}\left(\frac{\dot{\gamma}_{c}}{\dot{\gamma}_{0}}\right)^{-\frac{1}{n^{*}}} \dot{\gamma}_{c} \rho_{c}, \\
& \dot{\rho}_{w}=\frac{4 \beta^{*} \dot{\gamma}_{c} \sqrt{1-f}}{b d_{c} f}+\frac{2 \beta^{*} \dot{\gamma}_{c}(1-f)}{b f \sqrt{3}}-k_{0}\left(\frac{\dot{\gamma}_{w}}{\dot{\gamma}_{0}}\right)^{-\frac{1}{n^{*}}} \dot{\gamma}_{w} \rho_{w} .
\end{aligned}
$$


Here, $\alpha^{*}$ and $\beta^{*}, k_{0}, n^{*}$ are material factors and $\dot{\gamma}_{w}$ and $\dot{\gamma}_{c}$ are the shear strain rate of the walls and cell interiors respectively; these two terms are assumed to be equal due to compatibility along the interfaces between cell wall and interiors, i.e., $\gamma_{c}=\gamma_{w}=\gamma$. $\mathrm{f}$ is the volume fraction of cell walls as given in Equation (9), while $d_{c}$ denotes the cell size, calculated using Equation (10). It should be noted that elasticity is neglected in this model, which means that the total shear strain is equal to the plastic shear strain.

$$
\begin{gathered}
f=f_{\infty}+\left(f_{0}-f_{\infty}\right) \exp \left(\frac{-\gamma}{\widetilde{\gamma}}\right), \\
d_{c}=\frac{k^{\prime}}{\sqrt{\rho_{\text {total }}}} .
\end{gathered}
$$

$f_{\infty}$ and $f_{0}$ denote the saturation and peak values of $f$, while $\widetilde{\gamma}$ is a material constant. $k^{\prime}$ is considered to be a proportionality constant in the original model [16]; in an updated model by Galindo-Nava et al. [132] it is instead considered to be a variable related to temperature, Poisson's ratio $v$, and statistical entropy $\Delta S$ as shown in Equation (11).

$$
d_{c}=\frac{k^{\prime}}{\sqrt{\rho_{\text {total }}}}=\frac{24 \pi(1-v)}{(2+v)}\left(\frac{1}{2}+\frac{T \Delta S}{G b^{3}}\right) / \sqrt{\rho_{\text {total }}} .
$$

The total dislocation density $\rho_{\text {total }}$ can be described as:

$$
\rho_{\text {total }}=f \rho_{w}+(1-f) \rho_{c} .
$$

Given the predicted dislocation density, the shear stress, $\tau$, can be expressed according to Mecking and Kocks $[133,134]$ as:

$$
\tau_{x}=\alpha M G b \sqrt{\rho_{x}}
$$

where $x$ indicates either $w$ (wall) or $c$ (cell interior). In addition, the average dislocation structure misorientation angle $\theta_{\text {dis }}$ can be also be related to dislocation density according to [135,136]:

$$
\theta_{d i s}=\arctan \left(b \sqrt{\rho_{w}^{g}}\right) \cong b \sqrt{\rho_{w}^{g}}
$$

where $\rho_{w}^{g}$ is the density of geometrically necessary dislocations, i.e., the wall dislocations that contribute to the misorientation build-up. The evolution rate of $\rho_{w}^{g}$ can be described as:

$$
\dot{\rho}_{w}^{g}=\xi \frac{6 \lambda \dot{\gamma}(1-f)^{2 / 3}}{b d_{c} f}
$$

where $\lambda$ and $\xi$ are material constants and $\xi$ denotes the fraction of dislocations moving from cell interiors into cell walls.

In summary, dislocation-based models describe the mechanical behaviour of materials using Equation (13), where the dislocation density of cell interiors and walls are included. The integration of Equations (7)-(15) characterises the viscoplastic flow and microstructural evolution during hot deformation.

Figure 18 shows the predicted and experimental viscoplastic behaviour and the associated dislocation evolution, using the dislocation-based modelling method, for an Al-Cu-Mg alloy [137]. Excellent agreement was achieved between experimental and simulated stress-strain curves (Figure 18a). Additionally, such a model can predict the evolutions and interactions between different types of dislocations, as shown in Figure 18b, providing some insights into the microstructures. 


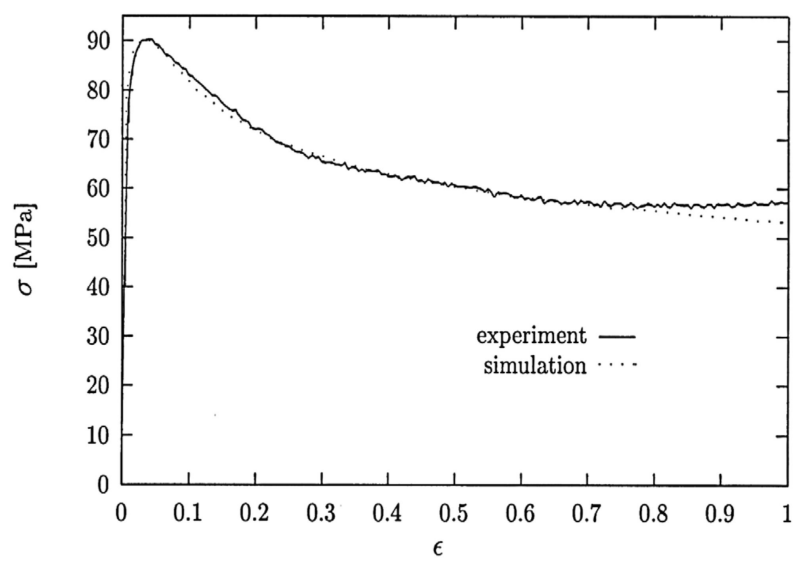

(a)

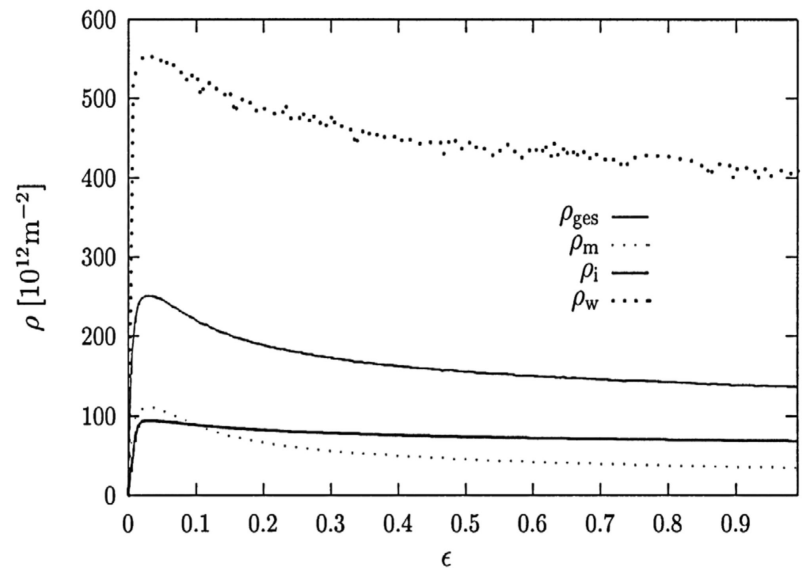

(b)

Figure 18. Predictions of the stress-strain curve and the associated dislocation evolution in Al-4.16 $\mathrm{wt} \% \mathrm{Cu}-1.37 \% \mathrm{Mg}$ during compression at $350{ }^{\circ} \mathrm{C}$ with a strain rate of $10^{-3} \mathrm{~s}^{-1}$. (a) Experimental (dots) and predicted (solid line) stress-strain curve. (b) Predicted dislocation density evolution, where $\rho_{\text {ges }}$, $\rho_{m}, \rho_{i}$ and $\rho_{w}$ represent the total dislocation density, mobile dislocation density, immobile dislocation density in cell interiors and immobile dislocation density cell walls, respectively (Reproduced with permission from Elsevier [137]).

\subsection{Semi-Dislocation-Based Models}

Unlike the dislocation-based approach, semi-dislocation-based models analyse the microstructure in terms of grains instead of dislocation cells. 'Dislocations', in this modelling approach, refers specifically to grain interior dislocations, and the grain size is considered using a separate variable $d$. The most widely used model to characterise the effect of grain size is the Hall-Petch equation, where the stress is inversely proportional to the square root of grain size, $\sigma \propto d^{-1 / 2}$ [15]. In this case, the flow stress can be expressed as [18]:

$$
\sigma=k+\alpha M G b \sqrt{\rho}+k_{d} d^{-\frac{1}{2}},
$$

where $\alpha$ and $k_{d}$ are material constants. The value of $k_{d}$ can be negative, corresponding to the softening mechanism during recrystallisation. $k$ is the threshold stress for the activation of dislocation slip; this quantity is considered to be a material constant at constant temperature and strain rate.

The dislocation density in the semi-dislocation-based model is expressed by Equation (17) [18],

$$
\dot{\rho}=\frac{M}{b}\left(\frac{\sqrt{\rho}}{f_{w}}+\frac{1}{d}\right) \dot{\varepsilon}_{p}-f_{v} \rho \dot{\varepsilon}_{p}-H\left(\rho-\rho_{c r}\right) S f \rho_{c r},
$$


where $f_{w}$ and $f_{v}$ are constant coefficients related to work-hardening and dynamic recovery, respectively. The first term of this equation represents dislocation generation during work-hardening, and $\frac{\sqrt{\rho}}{f_{w}}+\frac{1}{d}$ is the mean free path of dislocation slip. The second term indicates the dislocation annihilation during recovery. $H\left(\rho-\rho_{c r}\right)$ is the step function for detecting the onset of recrystallisation; here $\rho_{c r}$ is the critical dislocation density for the onset of recrystallisation, which can be determined as a power function of the strain rate. $S$ is the DRX volume fraction, which is usually considered to be proportional to stress or to be an exponential function of strain. The grain size is expressed as:

$$
d=S d_{d r x}+(1-S) d_{0}
$$

where $d_{d r x}$ and $d_{0}$ are the recrystallised and initial grain sizes, respectively. $d_{d r x}$ depends strongly on temperature, strain rate and initial grain size, and is calculated as:

$$
d_{d r x}=A_{r} d_{0}{ }^{m_{r}}\left(\dot{\varepsilon}_{p} \exp \left(\frac{Q}{k_{B} T}\right)\right)^{n_{r}},
$$

where $Q$ is an experimentally determined activation energy and $k_{B}$ is the Boltzmann constant. $A_{r}$, $m_{r}$ and $n_{r}$ are material constants, where $n_{r}$ is negative since increasing the strain rate can facilitate recrystallisation by inhibiting recovery.

Although it is not necessary to determine the misorientation evolution to complete the model set, the misorientation evolution of LAGB and HAGB can also be derived from dislocation density, grain size and strain rate [90]:

$$
\begin{gathered}
\dot{\theta}_{L A G B}=\frac{b}{2 N}(1-\beta) r \rho d \dot{\varepsilon}_{p}, \\
\dot{\theta}_{H A G B}=\left(1-\frac{b}{2 N}\right)(1-\beta) r \rho d \dot{\varepsilon}_{p},
\end{gathered}
$$

where $r$ is a material parameter indicating recovery, and is a function of strain rate and temperature, $\beta$ is the fraction of dislocations that contribute to further dislocation generation, and $N$ is the number of dislocations per unit area of boundary. Therefore, $1-\beta$ denotes the fraction of dislocations that are absorbed by pre-existing (sub)grain boundaries, $\frac{b}{2 N}$ of which are specifically absorbed by LAGB and the others by HAGB.

In contrast to the dislocation-based model, the semi-dislocation-based model considers the evolution of both the dislocation density and the grain size during deformation. Figure 19a presents an example of stress-strain curves predicted using the semi-dislocation-based model for AA1050 with different initial grain sizes, and demonstrates good agreement with test results. The evolution of grain sizes predicted for different $\mathrm{Al}$ alloys using this model is shown in Figure 19b [138].



(a)

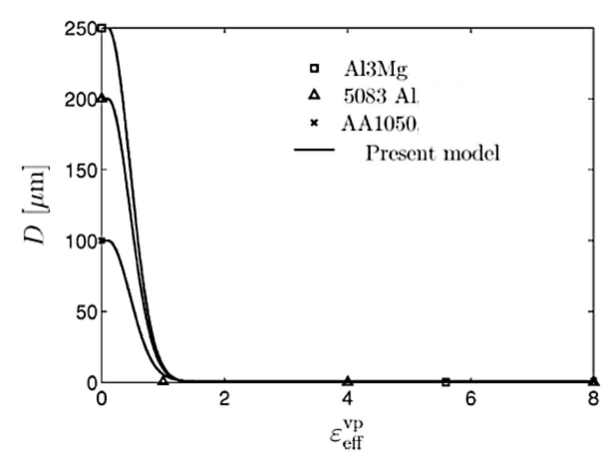

(b)

Figure 19. Comparison of predicted stress-strain curves and grain sizes using the semi-dislocation-based modelling method, with experimental results. (a) Stress-strain curves for AA1050 after different numbers of ECAP passes. (b) Evolution of grain size, $D$, for different $\mathrm{Al}$ alloys. Symbols represent experimental results while solid lines represent computed results (Reproduced with permission from Elsevier [138]). 


\subsection{Physically Based Models}

A physically based constitutive model, in terms of a set of equations derived by synthesising multifarious microstructural factors, was first presented by Lin et al. in $2005[19,20]$ and is shown in Equation (22):

$$
\begin{gathered}
\dot{\varepsilon}_{p}=f\left(\sigma, y_{2}, \cdots, y_{N E}, T\right), \\
\dot{y}_{2}=f_{2}\left(\varepsilon^{p}, y_{2}, \cdots y_{N E}, T, \dot{\varepsilon}_{p}, \dot{y}_{3}, \cdots, \dot{y}_{N E}\right), \\
\dot{y}_{N E}=f_{2}\left(\varepsilon_{p}, y_{2}, \cdots y_{N E}, T, \dot{\varepsilon}_{p}, \dot{y}_{2}, \cdots, \dot{y}_{N E-1}\right),
\end{gathered}
$$

where $y_{i}(i=2,3, \cdots, N E)$ are internal state variables. This formulation gives a user-friendly modelling framework so that researchers can add whichever variables are necessary according to their research focus, not only dislocation density and grain size but also other microstructural variables such as grain boundary area and grain rotation. Equations (23)-(29) introduce a classical unified equation set which can predict a wide range of time-dependent phenomena: plastic strain level in Equation (23), hardening level in Equation (24), dislocation density in Equation (25), grain size in Equation (26), recrystallised fraction in Equations (27) and (28) and viscoplastic flow rate in Equation (29) [20].

$$
\begin{gathered}
\dot{\varepsilon}_{p}=A_{1} \sinh \left[A_{2}(\sigma-R-k)\right]_{+} d^{-\gamma_{4}}, \\
\dot{R}=B \dot{\bar{\rho}} \\
\dot{\bar{\rho}}=\left(\frac{d}{d_{0}}\right)^{\gamma_{d}}(1-\bar{\rho})\left|\dot{\varepsilon}_{p}\right|-c_{1} \bar{\rho}^{c_{2}}-c_{3} \frac{\bar{\rho}}{1-S} \dot{S}, \\
\dot{d}=\alpha_{0} d^{-\gamma_{0}}-\alpha_{2} \dot{S}^{\gamma_{3}} d^{\gamma_{2}}, \\
\dot{S}=Q_{0}\left[x \bar{\rho}-\bar{\rho}_{c}(1-S)\right]_{+}(1-S)^{N_{q}}, \\
\dot{x}=A_{0}(1-x) \bar{\rho} \\
\dot{\sigma}=E\left(\dot{\varepsilon}-\dot{\varepsilon}_{p}\right)
\end{gathered}
$$

where $A_{1}, A_{2}, \gamma_{4}, \gamma_{d}, Q_{0}, \bar{\rho}_{c}, N_{q}, c_{1}, c_{2}, c_{3}, A_{0}, B, A_{0}, \alpha_{0}, \gamma_{0}, \alpha_{2}, \gamma_{2}, \gamma_{3}$ are material constants. $k$ is a constant value representing a threshold stress. $\bar{\rho}$ is the normalised dislocation density which takes values ranging from 0 to 1 [20]. $R$ corresponds to the hardening effect. $S$ is the recrystallised volume fraction, and $x$ is the recrystallisation incubation time. $S$ and $x$ together predict the occurrence and rate of DRX. The sign $[\cdots]_{+}$indicates that if the value within the bracket is negative, the rate of the corresponding process is 0 . All the variables interact and evolve together, resulting in the overall microscopic and macroscopic evolution during hot deformation. The details of each variable are described below in the following sequence: plastic strain rate $\dot{\varepsilon}_{p}$, hardening rate $\dot{R}$, dislocation density rate $\dot{\rho}$ and grain size rate $(\dot{d})$.

Different expressions from Equation (23) have also been used for the plastic strain rate, as shown in Equations (30) and (31) [139].

$$
\begin{gathered}
\dot{\varepsilon}_{p}=\dot{\varepsilon}_{0}\left[\frac{\sigma-R-k}{K}\right]_{+}^{n}, \\
\dot{\varepsilon}_{p}=\dot{\varepsilon}_{0}\left[\frac{\sigma-R-k}{K}\right]_{+}^{n} d^{-\mu},
\end{gathered}
$$

where $n, K, \mu$ and $\dot{\varepsilon}_{0}$ are material constants. The other parameters in this equation are defined in the Nomenclature.

The hardening rate $\dot{R}$ is assumed to be proportional to the rate of change of dislocation density in Equation (24). Since the hardening rate increases with an increasing plastic strain rate and rate of 
increase of dislocation density, it can also be expressed as in Equation (32) [140], Equation (33) [19] or Equation (34) [141].

$$
\begin{gathered}
\dot{R}=B(Q-R) \dot{\varepsilon}_{p}, \\
\dot{R}=\frac{1}{2} B \rho^{-0.5} \dot{\rho}, \\
\dot{R}=\frac{r_{0}}{\sigma}\left(1-\frac{R}{R^{*}}\right) \dot{\varepsilon}_{p},
\end{gathered}
$$

where $Q$ is the activation energy and $B, r_{0}$ and $R^{*}$ are material constants.

The normalised dislocation density $\bar{\rho}$ in Equation (25) is calculated as the sum of an increase during work hardening and decreases due to recovery and recrystallisation. Unlike in dislocation-based models, here the effect of grain size on dislocation generation is also considered, since a smaller grain size facilitates grain rotation and boundary sliding, resulting in less accumulation of dislocations [19]. One alternative formula is given in Equation (35) [20]:

$$
\dot{\rho}=M\left(k_{0}+k_{1} \sqrt{\rho}-k_{2} \rho\right)\left|\dot{\varepsilon}_{p}\right|-r_{0} \exp \left(-\frac{Q}{k_{B} T}\right) \sinh \left(\frac{\beta \sqrt{\rho}}{k_{B} T}\right),
$$

where $k_{0}, k_{1}, k_{2}, r_{0}$ and $\beta$ are material constants. $k_{1}, k_{2}$ and $r_{0}$ characterise the dislocation storage, annihilation during recovery and recrystallisation, respectively. $k_{B}$ denotes the Boltzmann constant and $Q$ the activation energy.

The grain size evolution in Equation (26) results from the competition between grain growth induced by boundary energy reduction (first term) and grain refinement induced by recrystallisation (second term). Another similar expression is given in Equation (36) [19],

$$
\dot{d}=\alpha_{0} d^{-\gamma_{0}}+\alpha_{1} \dot{\varepsilon}_{p} d^{-\varnothing}-\alpha_{2} \dot{S}^{\gamma_{3}} d^{\gamma_{2}}
$$

where $\alpha_{0}, \alpha_{1}, \alpha_{2}, \gamma_{0}, \gamma_{2}, \gamma_{3}$ and $\varnothing$ are constants. The first term in this equation is related to the isothermal grain growth and the second term characterises the strain rate dependence. The third term is related to the recrystallisation effect. The grain size expression in Equation (26) neglects the second term because its corresponding mechanism is considered less important than the other two mechanisms.

It should be noted that the internal variables $x$ in Equation (28) and $S$ in Equation (27) were introduced to represent the incubation time of nucleation and the evolution of recrystallised volume fraction during the processes of grain nucleation and growth, based on the mechanism of DDRX. For CDRX, however, different mechanisms and microstructural evolution take place during hot deformation. This model has been modified to characterise CDRX for the hot deformation of $\mathrm{Al}$ alloys using different representative variables such as subgrain rotation and GB areas [142,143]. The CDRX-based models consider the evolution of dislocations, LAGB and HAGB, and are based on physical phenomena including accumulation, migration, rotation and annihilation of these microstructural constituents. For example, both migration of LAGB and rotation of subgrains lead to an increase in the misorientation angle of LAGB, which turn into HAGB after reaching a critical angle. The CDRX-based models have been shown to be in good agreement with experimental data for some aluminium alloys. For GDRX, however, there is still no relevant physically based model that characterises its mechanism in particular.

Figure 20 is as an example showing the predictions of the viscoplastic behaviour and the associated microstructures of AA7075 during compression with various strain rates and temperatures, using a physically-based model [143]. Overall, reasonable predictions were achieved under the temperature and strain rate ranges studied, especially for the flow stress curves. It should be mentioned that the predictions from the model give acceptable trends for all essential microstructural variables, but do not agree perfectly with experiments. For an alloy containing different types of constituents, defects, impurities, etc, obtaining accurate and statistically meaningful microstructural data during deformation 
for model calibration is not always possible. However, such modelling methods provide a way to describe the microstructural trends, enabling a global understanding of the deformation mechanisms.

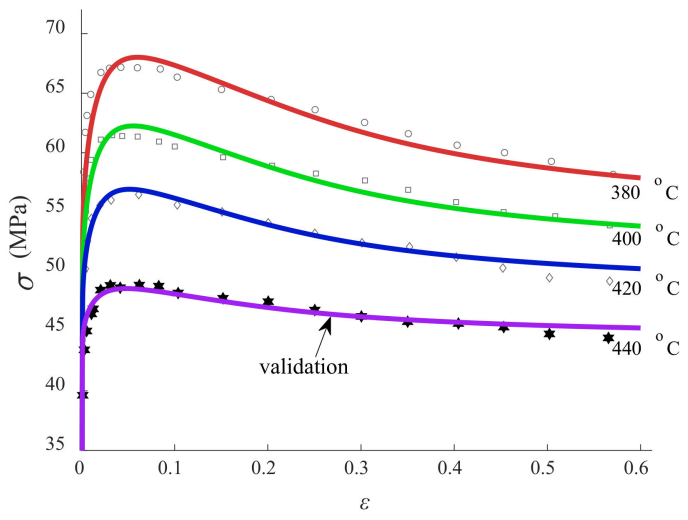

(a)

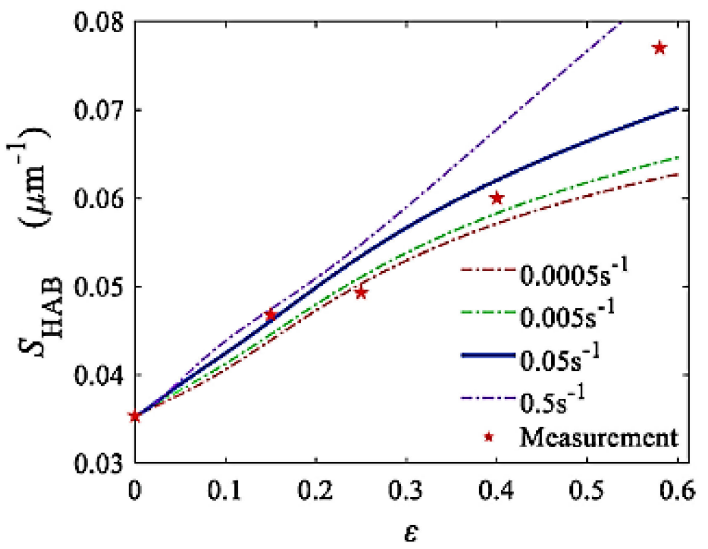

(c)



(b)

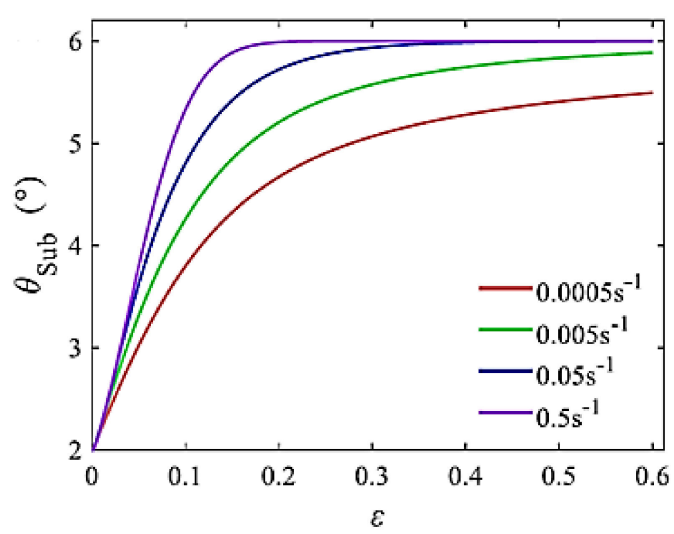

(d)

Figure 20. Experimental (symbols) and computed (solid lines) for compression of AA7075: (a) stress-strain curves for different temperatures and a constant strain rate of $0.05 \mathrm{~s}^{-1} ;$ (b) stress-strain curves for different strain rates at a constant temperature of $420^{\circ} \mathrm{C}$; (c) high angle grain boundary area per unit volume, $S_{H A B}$, for the conditions in (b); (d) subgrain misorientations, $\theta_{\text {sub }}$, for the conditions in (b). Note that the symbols in (c) represent the $S_{H A B}$ measured at a strain rate of $0.05 \mathrm{~s}^{-1}$ and a temperature of $420{ }^{\circ} \mathrm{C}$. (Reproduced with permission from Elsevier [143]).

A summary of the advantages and disadvantages of the abovementioned material modelling approaches is presented in Table 1. Empirical, dislocation-based, semi-dislocation-based and physically based models are listed in chronological order. The more recent models are usually better at characterising the relations between microstructures and viscoplasticity. However, increasing numbers of material parameters and internal variables also make the simulation harder. 
Table 1. Summary and comparison of different kinds of modelling approaches.

\begin{tabular}{ccccc}
\hline Expression & $\begin{array}{c}\text { Empirical Model } \\
\text { (1914-) }\end{array}$ & $\begin{array}{c}\text { Dislocation-Based Model } \\
\text { (1998-) }\end{array}$ & $\begin{array}{c}\text { Semi-Dislocation- } \\
\text { Based Model (2003-) }\end{array}$ & $\begin{array}{c}\text { Physically Based Model } \\
\text { (2005-) }\end{array}$ \\
\hline $\begin{array}{c}\text { Major research } \\
\text { group }\end{array}$ & $\begin{array}{c}\text { E. Andrade's group } \\
\text { (UK) }\end{array}$ & Y. Estrin's group (Australia) & $\begin{array}{c}\text { S. Gourdet's group } \\
\text { (France) }\end{array}$ & J. Lin's group (UK) \\
\hline Advantage & $\begin{array}{c}\text { Easily describe } \\
\text { viscoplastic } \\
\text { behaviour } \\
\text { phenomenologically }\end{array}$ & $\begin{array}{c}\text { In-depth analysis and } \\
\text { modelling of different types } \\
\text { of dislocations and their } \\
\text { influences on viscoplasticity }\end{array}$ & $\begin{array}{c}\text { In-depth analysis and } \\
\text { modelling of both } \\
\text { dislocation density and } \\
\text { grain size, and their } \\
\text { influences on } \\
\text { viscoplasticity }\end{array}$ & $\begin{array}{c}\text { Provide a modelling } \\
\text { framework to consider all } \\
\text { important physical variables. } \\
\text { Indicate the integrated } \\
\text { relations between } \\
\text { microstructures and } \\
\text { viscoplasticity }\end{array}$ \\
\hline Disadvantage & $\begin{array}{c}\text { Not able to model } \\
\text { any microstructural } \\
\text { evolution }\end{array}$ & $\begin{array}{c}\text { The number of modelling } \\
\text { parameters is relatively high. } \\
\text { Predicted evolution of } \\
\text { various types of dislocations } \\
\text { is difficult to validate } \\
\text { experimentally }\end{array}$ & $\begin{array}{c}\text { Influence of } \\
\text { dislocations on grain } \\
\text { sizes is not considered }\end{array}$ & $\begin{array}{c}\text { The number of modelling } \\
\text { parameters is high }\end{array}$ \\
\hline
\end{tabular}

\section{Conclusions and Perspectives}

\subsection{Conclusions}

In this review paper, mechanisms of recrystallisation have been discussed in detail. The microstructural evolution and viscoplastic behaviour have been described schematically according to existing experimental results. Post-forming properties have been discussed with reference to grain size. Four kinds of modelling methods have been classified according to their modelling principles. On the basis of the above analysis, the conclusions are the following:

1. Collation of existing data reveals that continuous dynamic recrystallisation (CDRX) is the most commonly occurring type of dynamic recrystallisation in aluminium alloys under hot-forming conditions, while discontinuous dynamic recrystallisation (DDRX) prevails in highly pure Al and in $\mathrm{Al}$ alloys processed at low strain rates. Geometric dynamic recrystallisation (GDRX) may occur when the material is subjected to significant shear strains (e.g., torsion) at relatively high temperatures. For as-quenched heat-treatable aluminium alloys, CDRX dominates at a strain rate $>10^{-3} \mathrm{~s}^{-1}$ and a temperature $>300^{\circ} \mathrm{C}$, while a transition from CDRX to DDRX was reported at low strain rates. For heat-treatable aluminium alloys in T6 condition, CDRX dominates for most forming conditions.

2. Quantitative data on microstructural evolutions with and without recrystallisation show that the dislocation density decreases when dynamic recrystallisation (DRX) occurs, but instead increases to a saturate value without DRX. When DRX occurs, the LAGB misorientation gradually increases to an average value of $3-8^{\circ}$, whereby the misorientation of a small fraction of LAGB continuously increases to $15^{\circ}$ such that these transform to HAGB, hence reducing the grain size. These microstructural changes lead to softening on the flow stress curves: a single peak and a subsequent softening stress-strain curve with CDRX and GDRX, but multiple peaks followed by a decrease with DDRX. Without DRX, the LAGB misorientation only increases up to 2-3 $3^{\circ}$.

3. The post-forming mechanical properties of aluminium alloys show significant dependence on grain size. The yield strength increases linearly with $d^{1 / 2}$ for both pure aluminium and its alloys. When the grain size is larger than $10 \mu \mathrm{m}$, the yield strength becomes less sensitive to grain size, with increases in strength of within $100 \mathrm{MPa}$. Material elongation increases rapidly when the grain size exceeds $\sim 1 \mu \mathrm{m}$, then stays unchanged with increasing grain size. When the grain size becomes larger than $\sim 1 / 4$ of the sample thickness, the elongation significantly drops. Both fatigue life and crack propagation rate are lower for larger grain sizes.

4. The associated modelling work, describing the recrystallisation and the viscoplastic behaviour under hot forming conditions, can be categorised into four types. Phenomenologically based 
empirical models were first introduced, describing viscoplastic behaviour in terms of the temperature and strain rate. (Semi-)dislocation-based models were later established to consider the microstructural evolution during work-hardening and recrystallisation. In the 21st century, physically based models have been proposed, focusing on the integral evolution during hot deformation, including the evolution of microstructural variables and their relationships, as well as the corresponding mechanical response.

\subsection{Perspective}

Despite the tremendous efforts that have been made in the research on recrystallisation and its relationship with mechanical properties, the microstructural mechanisms occurring during hot deformation and their consequences for mechanical properties are still far from being thoroughly clear. Many aspects need to be clarified, including but not limited to the following:

1. The differences between CDRX and GDRX are still unclear. Experimental observations in existing literature cannot show conclusively whether CDRX or GDRX is occurring due to the similarity of the resulting microstructures. For example, $C D R X$ is considered to be the fundamental mechanism in most cases of SPD due to the continuous increase of misorientation after each pass, but at the same time, original grains can become highly elongated, causing the grain thickness to decrease to subgrain size, which is the characteristic feature of GDRX.

2. Building a comprehensive recrystallisation map that accounts quantitatively for the effects of strain, strain rate, temperature, initial grain size, material purity, etc, would be of great value. A recrystallisation map in terms of temperature and strain rate has been presented in this review paper based on existing data. However, different types of recrystallisation may occur together and there is a lack of research showing a clearly distinguishable transition between different types of recrystallisation and the relative contribution of each type under various deformation conditions.

3. More mechanism-based constitutive equations, incorporating the key deformation mechanisms, would be of great value to link the fundamental science to industrial practice for hot forming processes. These should be able to accurately describe the material flow behaviour, the microstructures and the post-deformation properties. The development of such models should be based on clear and quantitative understanding of the mechanisms under hot forming conditions.

4. More testing and metallographic observations are needed to understand the microstructural evolution during hot deformation. For example, the effect of strain rate on misorientation evolution is still not well understood. Whether the volume fraction of dislocation walls in dislocation cells goes up or down with strain and temperature is still unclear. The influence of dislocation density on flow stress is difficult to quantify. New advanced techniques could play an important role in resolving these problems.

Author Contributions: Conceptualization, J.-H.Z., Z.S. and J.L. (Jianguo Lin); methodology, J.L. (Jiaxin Lv), J.-H.Z., Z.S. and J.L. (Jianguo Lin); validation, J.L. (Jiaxin Lv), J.-H.Z. and V.A.Y.; formal analysis, J.L. (Jiaxin Lv); investigation, J.L. (Jiaxin Lv), J.-H.Z. and V.A.Y.; data curation, J.L. (Jiaxin Lv); writing — original draft preparation, J.L. (Jiaxin Lv); writing—review and editing, J.L. (Jiaxin Lv), J.-H.Z., V.A.Y., Z.S. and J.L. (Jianguo Lin); visualization, J.L. (Jiaxin Lv); supervision, J.-H.Z., Z.S. and J.L. (Jianguo Lin); project administration, Z.S. and J.L. (Jianguo Lin); funding acquisition, Z.S. and J.L. (Jianguo Lin). All authors have read and agreed to the published version of the manuscript.

Funding: This research was funded by LightForm: Embedding Materials Engineering in Manufacturing with Light Alloys, grant number EP/R001715/1, Beijing Institute of Aeronautical Materials (BIAM), China under MESM_P42745, and the President's PhD Scholarship of Imperial College London.

Acknowledgments: The author (J. Lv) is grateful for the financial support from the President's PhD Scholarship of Imperial College London. The authors would like to thank the funding support by EPSRC under the Grant Agreement EP/R001715/1 on "LightForm: Embedding Materials Engineering in Manufacturing with Light Alloys" and Beijing Institute of Aeronautical Materials (BIAM), China under the grant number of MESM_P42745.

Conflicts of Interest: The authors declare no conflict of interest. 


\section{Nomenclature}

$b$

$d, d_{0}, d_{f}$

$d_{c}$

E

$f, f_{0}, f_{\infty}$

$G$

$k_{B}$

$k$

$k_{d}$

$M$

N

$Q$

R

$r$

$S$

$T, T_{m}$

U

$v$

$x$

Z

$\sigma, \sigma_{D R V}, \sigma_{p e}, \sigma_{s s}$

$\varepsilon, \varepsilon_{0}, \varepsilon_{c}, \varepsilon_{p e}, \varepsilon_{p}$

$\rho, \rho_{0}, \rho_{\text {total }}, \rho_{c r}, \bar{\rho}$

$\rho_{c}, \rho_{w}, \rho_{L A G B}, \rho_{w}^{g}$

$\bar{\rho}$

$\theta_{L A G B}, \theta_{H A G B}, \theta_{d i s}$

$\gamma_{w}, \gamma_{c}, \gamma_{0}$

$\Omega$

$\Delta S$

$X, \dot{X}$
Burgers vector

Grain size, its initial value and saturation value, respectively

Dislocation cell size

Young's modulus

Volume fraction of cell walls, its peak value and saturation value respectively

Shear modulus

Boltzmann constant

Threshold stress

Grain size factor

Dislocation mobility

Number of dislocations in grain boundary

Activation energy

Hardening factor

Recovery parameter

DRX volume fraction

Temperature and melting temperature, respectively

Work hardening parameter

Poison ratio

Onset of recrystallisation

Zener-Hollomon parameter

Flow stress, steady state stress due to recovery, peak stress, and steady state stress due to recrystallisation, respectively

Strain, reference strain, critical strain for occurring dynamic recrystallisation, peak strain and plastic strain, respectively

Dislocation density, its initial value, total value, and critical value for recrystallisation, respectively

Dislocation density in cell interior, cell wall and LAGB, and geometrically necessary

dislocation density in cell walls, respectively

Normalised dislocation density

Misorientation of LAGB, HAGB and dislocation structures, respectively

Shear of cell wall, cell interior and reference shear, respectively

Dynamic recovery parameter

statistical entropy

Any variable $X$ and its time derivative, respectively

Material constants: $A_{0}, A_{1}, A_{2}, A_{r}, A^{*}, B^{*}, B, C^{*}, c_{1}, c_{2}, c_{3}, f_{w}, f_{v}, K_{d}, k^{\prime}, k_{0}, k_{1}, k_{2}, m, m_{1}, m_{2}, m_{r}, N_{q}, n, n_{r}, n_{d}, n^{*}$, $Q, Q_{0}, R^{*}, r_{0}, \alpha, \alpha_{0}, \alpha_{1}, \alpha_{2}, \alpha^{*}, \beta, \beta^{*}, \bar{\rho}_{c^{\prime}}, \rho_{r e f}, \gamma_{0}, \gamma_{2}, \gamma_{4}, \gamma_{d}, \widetilde{\gamma}^{r}, \varnothing, \xi, \lambda, K, \mu$.

\section{References}

1. Toros, S.; Ozturk, F.; Kacar, I. Review of warm forming of aluminum-magnesium alloys. J. Mater. Process. Technol. 2008, 207, 1-12. [CrossRef]

2. Belov, N.A.; Eskin, D.G.; Aksenov, A.A. Introduction. In Multicomponent Phase Diagrams: Applications for Commercial Aluminum Alloys, 1st ed.; Elsevier Science: Oxford, UK, 2005; pp. 5-6.

3. Lin, J.; Ho, K.; Dean, T. An integrated process for modelling of precipitation hardening and springback in creep age-forming. Int. J. Mach. Tools Manuf. 2006, 46, 1266-1270. [CrossRef]

4. El Fakir, O.; Wang, L.; Balint, D.; Dear, J.P.; Lin, J.; Dean, T.A. Numerical study of the solution heat treatment, forming, and in-die quenching (HFQ) process on AA. Int. J. Mach. Tools Manuf. 2014, 87, 39-48. [CrossRef]

5. Scharifi, E.; Knoth, R.; Weidig, U. Thermo-mechanical forming procedure of high strength Aluminum sheet with improved mechanical properties and process efficiency. Procedia Manuf. 2019, 29, 481-489. [CrossRef]

6. Kleiner, M.; Chatti, S.; Klaus, A. Metal forming techniques for lightweight construction. J. Mater. Process. Technol. 2006, 177, 2-7. [CrossRef]

7. Raabe, D. Recovery and recrystallization: Phenomena, physics, models, simulation. In Physical Metallurgy, 5th ed.; Laughlin, D.E., Hono, K., Eds.; Elsevier: Amsterdam, The Netherlands, 2014; pp. 2291-2397. 
8. Snopiński, P.; Król, M. Microstructure, mechanical properties and strengthening mechanism analysis in an AlMg5 aluminium alloy processed by ECAP and subsequent ageing. Metals 2018, 8, 969. [CrossRef]

9. Li, H.; Hu, Z.; Hua, L.; Sun, Q. Influence of thermal deformation parameters on mechanical properties and microstructure evolution of AA7075 aluminum alloy during hot stamping-quenching process. JOM 2019, 71, 4778-4788. [CrossRef]

10. Kamachali, R.D. Grain Boundary Motion in Polycrystalline Materials. Ph.D. Thesis, Ruhr-Universität Bochum, Bochum, Germany, 2013.

11. Pettersen, T.; Holmedal, B.; Nes, E. Microstructure development during hot deformation of aluminum to large strains. Met. Mater. Trans. A 2003, 34, 2737-2744. [CrossRef]

12. Yamagata, H. Dynamic recrystallization of single-crystalline aluminum during compression tests. Scr. Met. Mater. 1992, 27, 727-732. [CrossRef]

13. Huang, K.; Logé, R. A review of dynamic recrystallization phenomena in metallic materials. Mater. Des. 2016, 111, 548-574. [CrossRef]

14. Gashti, S.; Fattah-Alhosseini, A.; Mazaheri, Y.; Keshavarz, M. Effects of grain size and dislocation density on strain hardening behavior of ultrafine grained AA1050 processed by accumulative roll bonding. J. Alloys Compd. 2016, 658, 854-861. [CrossRef]

15. Petch, N.J. The cleavage strength of polycrystals. J. Iron Steel Inst. 1953, 174, 25-28.

16. Estrin, Y.; Tóth, L.; Molinari, A.; Bréchet, Y. A dislocation-based model for all hardening stages in large strain deformation. Acta Mater. 1998, 46, 5509-5522. [CrossRef]

17. He, X.; Liu, L.; Zeng, T.; Yao, Y. Micromechanical modeling of work hardening for coupling microstructure evolution, dynamic recovery and recrystallization: Application to high entropy alloys. Int. J. Mech. Sci. 2020, 177, 105567. [CrossRef]

18. Lin, Y.; Wen, D.-X.; Chen, M.-S.; Chen, X.-M. A novel unified dislocation density-based model for hot deformation behavior of a nickel-based superalloy under dynamic recrystallization conditions. Appl. Phys. A 2016, 122, 805. [CrossRef]

19. Lin, J. Fundamentals of Materials Modelling for Metals Processing Technologies: Theories and Applications; Imperial College Press: London, UK; Hackensack, NJ, USA, 2015.

20. Lin, J.; Liu, Y.; Farrugia, D.C.; Zhou, M. Development of dislocation-based unified material model for simulating microstructure evolution in multipass hot rolling. Philos. Mag. 2005, 85, 1967-1987. [CrossRef]

21. Sakai, T.; Belyakov, A.; Kaibyshev, R.; Miura, H.; Jonas, J.J. Dynamic and post-dynamic recrystallization under hot, cold and severe plastic deformation conditions. Prog. Mater. Sci. 2014, 60, 130-207. [CrossRef]

22. Rios, P.R.; Siciliano, F., Jr.; Sandim, H.R.Z.; Plaut, R.L.; Padilha, A.F. Nucleation and growth during recrystallization. Mater. Res. 2005, 8, 225-238. [CrossRef]

23. Kassner, M.; Barrabes, S. New developments in geometric dynamic recrystallization. Mater. Sci. Eng. A 2005, 410, 152-155. [CrossRef]

24. Yamagata, H.; Co, L.Y.M. Microstructural evolution of single-crystalline aluminum during multipeak stress oscillation at 623 K. Scr. Metall. Mater. 1992, 27, 1157-1160. [CrossRef]

25. Yamagata, H. Multipeak stress oscillations of five-nine-purity aluminum during a hot compression test. Scr. Met. Mater. 1992, 27, 201-203. [CrossRef]

26. Ponge, D.; Bredehöft, M.; Gottstein, G. Dynamic recrystallization in high purity aluminum. Scr. Mater. 1997, 37, 1769-1775. [CrossRef]

27. Yamagata, H. Dynamic recrystallization and dynamic recovery in pure aluminum at 583K. Acta Met. Mater. 1995, 43, 723-729. [CrossRef]

28. Stipp, M.; Stünitz, H.; Heilbronner, R.; Schmid, S.M. The eastern Tonale fault zone: A 'natural laboratory' for crystal plastic deformation of quartz over a temperature range from 250 to $700{ }^{\circ}$ C. J. Struct. Geol. 2002, 24, 1861-1884. [CrossRef]

29. Kaibyshev, R.; Sitdikov, O.; Goloborodko, A.; Sakai, T. Grain refinement in as-cast 7475 aluminum alloy under hot deformation. Mater. Sci. Eng. A 2003, 344, 348-356. [CrossRef]

30. Horita, Z.; Fujinami, T.; Nemoto, M.; Langdon, T.G. Equal-channel angular pressing of commercial aluminum alloys: Grain refinement, thermal stability and tensile properties. Met. Mater. Trans. A 2000, 31, 691-701. [CrossRef]

31. Yang, X.; Miura, H.; Sakai, T. Continuous Dynamic Recrystallization in a Superplastic 7075 Aluminum Alloy. Mater. Trans. 2002, 43, 2400-2407. [CrossRef] 
32. Canelo-Yubero, D.; Kovács, Z.; Fotso, J.T.S.; Tolnai, D.; Schell, N.; Groma, I.; Poletti, C. In-situ characterization of continuous dynamic recrystallization during hot torsion of an Al-Si-Mg alloy. J. Alloy. Compd. 2020, 822, 153282. [CrossRef]

33. Poletti, M.C.; Simonet-Fotso, T.; Halici, D.; Canelo-Yubero, D.; Montheillet, F.; Piot, D.; Kovács, Z.; Schell, N.; Tolnai, D. Continuous dynamic recrystallization during hot torsion of an aluminum alloy. J. Phys. Conf. Ser. 2019, 1270, 012049. [CrossRef]

34. Zhao, J.; Deng, Y.; Tan, J.; Zhang, J. Effect of strain rate on the recrystallization mechanism during isothermal compression in 7050 aluminum alloy. Mater. Sci. Eng. A 2018, 734, 120-128. [CrossRef]

35. Gourdet, S.; Montheillet, F. An experimental study of the recrystallization mechanism during hot deformation of aluminium. Mater. Sci. Eng. A 2000, 283, 274-288. [CrossRef]

36. Mazahery, A. Ways of Describing Grain Boundaries and Types of Grain Boundaries. Technical Report. 2018. Available online: https://www.researchgate.net/publication/328729635 (accessed on 20 April 2020).

37. Blum, W.; Zhu, Q.; Merkel, R.; McQueen, H. Geometric dynamic recrystallization in hot torsion of Al-5Mg-0.6Mn (AA5083). Mater. Sci. Eng. A 1996, 205, 23-30. [CrossRef]

38. Humphreys, F.; Kalu, P. Dislocation-particle interactions during high temperature deformation of two-phase aluminium alloys. Acta Met. 1987, 35, 2815-2829. [CrossRef]

39. Liao, B.; Wu, X.; Cao, L.; Huang, G.; Wang, Z.; Liu, Q. The microstructural evolution of aluminum alloy 7055 manufactured by hot thermo-mechanical process. J. Alloy. Compd. 2019, 796, 103-110. [CrossRef]

40. Yang, Q.; Deng, Z.; Zhang, Z.; Liu, Q.; Jia, Z.; Huang, G. Effects of strain rate on flow stress behavior and dynamic recrystallization mechanism of Al-Zn-Mg-Cu aluminum alloy during hot deformation. Mater. Sci. Eng. A 2016, 662, 204-213. [CrossRef]

41. Kaibyshev, R.; Malopheyev, S. Mechanisms of dynamic recrystallization in aluminum alloys. Mater. Sci. Forum 2014, 794, 784-789. [CrossRef]

42. Ito, Y.; Horita, Z. Microstructural evolution in pure aluminum processed by high-pressure torsion. Mater. Sci. Eng. A 2009, 503, 32-36. [CrossRef]

43. Bricknell, R.H.; Edington, J.W. Deformation characteristics of an Al-6Cu-O. 4Zr superplastic alloy. Met. Mater. Trans. A 1979, 10, 1257-1263. [CrossRef]

44. Zhang, H.; Li, L.; Yuan, D.; Peng, D. Hot deformation behavior of the new Al-Mg-Si-Cu aluminum alloy during compression at elevated temperatures. Mater. Charact. 2007, 58, 168-173. [CrossRef]

45. Poortmans, S.; Verlinden, B. Mechanical Properties of Fine-Grained AA1050 after ECAP. Mater. Sci. Forum 2006, 503, 847-852. [CrossRef]

46. Quan, G.-Z.; Mao, Y.-P.; Li, G.-S.; Lv, W.-Q.; Wang, Y.; Zhou, J. A characterization for the dynamic recrystallization kinetics of as-extruded 7075 aluminum alloy based on true stress-strain curves. Comput. Mater. Sci. 2012, 55, 65-72. [CrossRef]

47. Hu, H.; Zhen, L.; Yang, L.; Shao, W.; Zhang, B. Deformation behavior and microstructure evolution of 7050 aluminum alloy during high temperature deformation. Mater. Sci. Eng. A 2008, 488, 64-71. [CrossRef]

48. Mazurina, I.; Sakai, T.; Miura, H.; Sitdikov, O.; Kaibyshev, R. Effect of deformation temperature on microstructure evolution in aluminum alloy 2219 during hot ECAP. Mater. Sci. Eng. A 2008, 486, 662-671. [CrossRef]

49. Kaibyshev, R.O.; Mazurina, I.A.; Gromov, D.A. Mechanisms of grain refinement in aluminum alloys in the process of severe plastic deformation. Met. Sci. Heat Treat. 2006, 48, 57-62. [CrossRef]

50. Zhilyaev, A.P.; Langdon, T. Using high-pressure torsion for metal processing: Fundamentals and applications. Prog. Mater. Sci. 2008, 53, 893-979. [CrossRef]

51. McQueen, H.J.; Ryan, N.D.; Konopleva, E.V.; Xia, X. Formation and application of grain boundary serrations. Can. Metall. Q. 1995, 34, 219-229. [CrossRef]

52. Kassner, M.E. 7-Recrystallization. In Fundamentals of Creep in Metals and Alloys, 2nd ed.; Kassner, M.E., Ed.; Elsevier: Amsterdam, The Netherlands, 2008; pp. 153-160.

53. Konopleva, E.; McQueen, H.; Evangelista, E. Serrated grain boundaries in hot-worked aluminum alloys at high strains. Mater. Charact. 1995, 34, 251-264. [CrossRef]

54. Kassner, M.E.; McMahon, M.E. The dislocation microstructure of aluminum. Met. Mater. Trans. A 1987, 18, 835-846. [CrossRef]

55. Gholinia, A.; Humphreys, F.; Prangnell, P. Production of ultra-fine grain microstructures in Al-Mg alloys by coventional rolling. Acta Mater. 2002, 50, 4461-4476. [CrossRef] 
56. McQueen, H.; Kassner, M. Comments on 'a model of continuous dynamic recrystallization' proposed for aluminum. Scr. Mater. 2004, 51, 461-465. [CrossRef]

57. Henshall, G.; Kassner, M.; McQueen, H. Comments on, “Dynamic recrystalization during hot compression in Al-Mg alloy". Scr. Met. Mater. 1993, 28, 151-156. [CrossRef]

58. Henshall, G.A.; Kassner, M.E.; McQueen, H.J. Dynamic restoration mechanisms in Al-5.8 At. Pct Mg deformed to large strains in the solute drag regime. Met. Mater. Trans. A 1992, 23, 881-889. [CrossRef]

59. Mazurina, I.; Sakai, T.; Miura, H.; Sitdikov, O.; Kaibyshev, R. Grain refinement in aluminum alloy 2219 during ECAP at $250^{\circ} \mathrm{C}$. Mater. Sci. Eng. A 2008, 473, 297-305. [CrossRef]

60. Liu, L.; Wu, Y.; Gong, H.; Li, S.; Ahmad, A.S. A physically based constitutive model and continuous dynamic recrystallization behavior analysis of 2219 Aluminum alloy during hot deformation process. Materials 2018, 11, 1443. [CrossRef]

61. Yan, L.M.; Shen, J.; Li, J.P.; Li, Z.B.; Tang, Z.L. Dynamic recrystallization of 7055 Aluminum alloy during hot deformation. Mater. Sci. Forum 2010, 650, 295-301. [CrossRef]

62. Yu, J.; Zhao, G.; Zhang, C.; Chen, L. Dynamic evolution of grain structure and micro-texture along a welding path of aluminum alloy profiles extruded by porthole dies. Mater. Sci. Eng. A 2017, 682, 679-690. [CrossRef]

63. Chovet, C.; Gourdet, S.; Montheillet, F. Modelling the transition from discontinuous to continuous dynamic recrystallization with decreasing purity in Aluminium. Mater. Trans. JIM 2000, 41, 109-112. [CrossRef]

64. Gleiter, H. The mechanism of grain boundary migration. Acta Met. 1969, 17, 565-573. [CrossRef]

65. Rhines, F.N.; Craig, K.R.; Dehoff, R.T. Mechanism of steady-state grain growth in aluminum. Met. Mater. Trans. A 1974, 5, 413-425. [CrossRef]

66. McCurry, N.M. Aluminum Temprature Coefficient of Resistance vs. Grain Structure. Master's Thesis, Lehigh University, Bethlehem, PA, USA, 1993.

67. Paidar, V.; Kadecková, S.; Lejček, P. Single grain boundary migration. Czechoslov. J. Phys. 1988, 38, 470-473. [CrossRef]

68. Novikov, V. Grain Growth and Control of Microstructure and Texture in Polycrystalline Materials; CRC Press: Boca Raton, FL, USA, 1997.

69. Asgharzadeh, H.; McQueen, H.J. Grain growth and stabilisation of nanostructured aluminium at high temperatures: Review. Mater. Sci. Technol. 2014, 31, 1016-1034. [CrossRef]

70. Xiong, Y.; Li, N.; Jiang, H.; Li, Z.; Xu, Z.; Liu, L. Microstructural evolutions of AA7055 Aluminum alloy under dynamic and quasi-static compressions. Acta Metall. Sin. 2014, 27, 272-278. [CrossRef]

71. Jana, S.; Mishra, R.S.; Baumann, J.; Grant, G. Effect of process parameters on abnormal grain growth during friction stir processing of a cast Al alloy. Mater. Sci. Eng. A 2010, 528, 189-199. [CrossRef]

72. Lipecka, J.; Andrzejczuk, M.; Lewandowska, M.; Janczak-Rusch, J.; Kurzydłowski, K.J. Evaluation of thermal stability of ultrafine grained aluminium matrix composites reinforced with carbon nanotubes. Compos. Sci. Technol. 2011, 71, 1881-1885. [CrossRef]

73. Bazarnik, P.; Lewandowska, M.; Andrzejczuk, M.; Kurzydłowski, K.J. The strength and thermal stability of Al-5Mg alloys nano-engineered using methods of metal forming. Mater. Sci. Eng. A 2012, 556, 134-139. [CrossRef]

74. Bommareddy, A.; Quadir, M.; Ferry, M. Time and temperature regime of continuous grain coarsening in an ECAP-processed Al(0.1 wt.\% Sc) alloy. J. Alloy. Compd. 2012, 527, 145-151. [CrossRef]

75. Yu, C.; Sun, P.; Kao, P.-W.; Chang, C. Evolution of microstructure during annealing of a severely deformed aluminum. Mater. Sci. Eng. A 2004, 366, 310-317. [CrossRef]

76. Goloborodko, A.; Ito, T.; Yun, X.; Motohashi, Y.; Itoh, G. Friction stir welding of a commercial 7075-T6 Aluminum alloy: Grain refinement, thermal stability and tensile properties. Mater. Trans. 2004, 45, 2503-2508. [CrossRef]

77. Wang, J.; Iwahashi, Y.; Horita, Z.; Furukawa, M.; Nemoto, M.; Valiev, R.; Langdon, T.G. An investigation of microstructural stability in an AlMg alloy with submicrometer grain size. Acta Mater. 1996, 44, 2973-2982. [CrossRef]

78. Lewandowska, M.; Kurzydłowski, K.J. Thermal stability of a nanostructured aluminium alloy. Mater. Charact. 2005, 55, 395-401. [CrossRef]

79. Hasegawa, H.; Komura, S.; Utsunomiya, A.; Horita, Z.; Furukawa, M.; Nemoto, M.; Langdon, T.G. Thermal stability of ultrafine-grained aluminum in the presence of $\mathrm{Mg}$ and $\mathrm{Zr}$ additions. Mater. Sci. Eng. A 1999, 265, 188-196. [CrossRef] 
80. Schober, T.; Balluffi, R.W. Quantitative observation of misfit dislocation arrays in low and high angle twist grain boundaries. Philos. Mag. 1970, 21, 109-123. [CrossRef]

81. Messerschmidt, U.; Bartsch, M. Generation of dislocations during plastic deformation. Mater. Chem. Phys. 2003, 81, 518-523. [CrossRef]

82. Frank, F.C.; Read, J.W.T. Multiplication processes for slow moving dislocations. Phys. Rev. 1950, 79, $722-723$. [CrossRef]

83. Estrin, Y. Dislocation theory based constitutive modelling: Foundations and applications. J. Mater. Process. Technol. 1998, 33-39. [CrossRef]

84. Gubicza, J.; Chinh, N.; Horita, Z.; Langdon, T. Effect of Mg addition on microstructure and mechanical properties of aluminum. Mater. Sci. Eng. A 2004, 55-59. [CrossRef]

85. Tolaminejada, B.; Taaheri, A.K.; Aribi, H.; Shahmiri, M. An investigation into the effect of ECAE process on mechanical and microstructural properties of middle layer in copper clad Aluminium composite. In Proceedings of the Iran International Aluminum Conference, Tehran, Iran, 20-23 April 2009.

86. Bratov, V.; Borodin, E. Comparison of dislocation density based approaches for prediction of defect structure evolution in aluminium and copper processed by ECAP. Mater. Sci. Eng. A 2015, 631, 10-17. [CrossRef]

87. Fujita, H. Continuous observation of dynamic behaviors of dislocations in Aluminum. J. Phys. Soc. Jpn. 1967, 23, 1349-1361. [CrossRef]

88. Yan, S.; Yang, H.; Li, H.; Yao, X. A unified model for coupling constitutive behavior and micro-defects evolution of aluminum alloys under high-strain-rate deformation. Int. J. Plast. 2016, 85, 203-229. [CrossRef]

89. Borodin, E.; Bratov, V. Non-equilibrium approach to prediction of microstructure evolution for metals undergoing severe plastic deformation. Mater. Charact. 2018, 141, 267-278. [CrossRef]

90. Gourdet, S.; Montheillet, F. A model of continuous dynamic recrystallization. Acta Mater. 2003, 51, $2685-2699$. [CrossRef]

91. Bate, P.; Hutchinson, W. Grain boundary area and deformation. Scr. Mater. 2005, 52, 199-203. [CrossRef]

92. Nes, E. Modelling of work hardening and stress saturation in FCC metals. Prog. Mater. Sci. 1997, 41, $129-193$. [CrossRef]

93. Marthinsen, K.; Nes, E. Modelling strain hardening and steady state deformation of Al-Mg alloys. Mater. Sci. Technol. 2001, 17, 376-388. [CrossRef]

94. Furu, T.; Rsund, R.; Nes, E. Substructure evolution during different hot deformation processes of commercial non-heat treatable aluminium alloys. Mater. Sci. Eng. A 1996, 214, 122-132. [CrossRef]

95. Sitdikov, O.; Avtokratova, E.; Sakai, T.; Tsuzaki, K. Ultrafine-grain structure formation in an Al-Mg-Sc alloy during warm ECAP. Met. Mater. Trans. A 2012, 44, 1087-1100. [CrossRef]

96. Sun, Z.; Zheng, L.-S.; Yang, H. Softening mechanism and microstructure evolution of as-extruded 7075 aluminum alloy during hot deformation. Mater. Charact. 2014, 90, 71-80. [CrossRef]

97. Ravichandran, N.; Prasad, Y.V.R.K. Dynamic recrystallization during hot deformation of aluminum: A study using processing maps. Met. Mater. Trans. A 1991, 22, 2339-2348. [CrossRef]

98. Wu, B.; Li, M.; Ma, D. The flow behavior and constitutive equations in isothermal compression of 7050 aluminum alloy. Mater. Sci. Eng. A 2012, 542, 79-87. [CrossRef]

99. Qian, G. Characterization for Dynamic Recrystallization Kinetics Based on Stress-Strain Curves; IntechOpen: London, UK, 2013. [CrossRef]

100. Takaki, T.; Yamanaka, A.; Tomita, Y. Phase-field modeling for dynamic recrystallization. In From Creep Damage Mechanics to Homogenization Methods: A Liber Amicorum to Celebrate the Birthday of Nobutada Ohno; Altenbach, H., Matsuda, T., Okumura, D., Eds.; Springer International Publishing: Cham, Switzerland, 2015; pp. 441-459.

101. Armstrong, R.W. Hall-Petch Relationship in Aluminum and Aluminum Alloys. Encycl. Alum. Alloy. 2019. [CrossRef]

102. Hayes, J.; Keyte, R.; Prangnell, P. Effect of grain size on tensile behaviour of a submicron grained Al-3 wt-\%Mg alloy produced by severe deformation. Mater. Sci. Technol. 2000, 16, 1259-1263. [CrossRef]

103. Werenskiold, J.C. Equal Channel Angular Pressing (ECAP) of AA6082: Mechanical Properties, Texture and Microstructural Development. Ph.D Thesis, Norwegian University of Science and Technology, Trondheim, Norway, 2004.

104. Kim, W.; Wang, J.; Choi, S.; Choi, H.; Sohn, H. Synthesis of ultra high strength Al-Mg-Si alloy sheets by differential speed rolling. Mater. Sci. Eng. A 2009, 520, 23-28. [CrossRef] 
105. Curle, U.; Govender, G. Semi-solid rheocasting of grain refined aluminum alloy. Trans. Nonferrous Met. Soc. China 2010, 20, s832-s836. [CrossRef]

106. Hansen, N. The effect of grain size and strain on the tensile flow stress of aluminium at room temperature. Acta Met. 1977, 25, 863-869. [CrossRef]

107. Fujita, H.; Tabata, T. The effect of grain size and deformation sub-structure on mechanical properties of polycrystalline aluminum. Acta Met. 1973, 21, 355-365. [CrossRef]

108. Liu, H.; Shen, Y.; Ma, J.; Zheng, P.; Zhang, L. Grain size dependence of uniform elongation in single-phase FCC/BCC metals. J. Mater. Eng. Perform. 2016, 25, 3599-3605. [CrossRef]

109. Kwok, H.W.H. Crack Nucleation Related Dislocation Dynamics-A Numerical Study on the FCC Metal. Master's Thesis, University of Ottawa, Ottawa, ON, Canada, 2011.

110. Mayén, J.; Abúndez, A.; Pereyra, I.; Colín, J.; Blanco, A.; Serna, S. Comparative analysis of the fatigue short crack growth on $\mathrm{Al} 6061-\mathrm{T} 6$ alloy by the exponential crack growth equation and a proposed empirical model. Eng. Fract. Mech. 2017, 177, 203-217. [CrossRef]

111. Chowdhury, P.; Sehitoglu, H. Mechanisms of fatigue crack growth-A critical digest of theoretical developments. Fatigue Fract. Eng. Mater. Struct. 2016, 39, 652-674. [CrossRef]

112. Elkhodary, K.I.; Zikry, M. Dynamic crack nucleation, propagation, and interactions with crystalline secondary phases in aluminum alloys subjected to large deformations. Philos. Mag. 2012, 92, 3920-3949. [CrossRef]

113. Wang, W.; Zhang, W.; Wang, H.; Fang, X.; Liang, X. Influence of grain boundary on the fatigue crack growth of 7050-T7451 Aluminum alloy based on small time scale method. Adv. Mater. Sci. Eng. 2016, 2016, 1-7. [CrossRef]

114. Hornbogen, E.; Gahr, K.-H.Z. Microstructure and fatigue crack growth in a $\gamma$-Fe-Ni-Al alloy. Acta Met. 1976, 24, 581-592. [CrossRef]

115. Balasubramanian, V.; Ravisankar, V.; Reddy, G.M. Effect of pulsed current welding on fatigue behaviour of high strength aluminium alloy joints. Mater. Des. 2008, 29, 492-500. [CrossRef]

116. Turnbull, A.; Rios, E.R.D.L. The effect of grain size on the fatigue of commercially pure Aluminium. Fatigue Fract. Eng. Mater. Struct. 1995, 18, 1455-1467. [CrossRef]

117. Shou, W.; Yi, D.; Liu, H.; Tang, C.; Shen, F.; Wang, B. Effect of grain size on the fatigue crack growth behavior of 2524-T3 aluminum alloy. Arch. Civ. Mech. Eng. 2016, 16, 304-312. [CrossRef]

118. Yin, D.; Liu, H.; Chen, Y.; Yi, D.; Wang, B.; Wang, B.; Shen, F.; Fu, S.; Tang, C.; Pan, S. Effect of grain size on fatigue-crack growth in 2524 aluminium alloy. Int. J. Fatigue 2016, 84, 9-16. [CrossRef]

119. Andrade, E.N.D.C. The flow in metals under large constant stresses. Proc. R. Soc. London. Ser. A Math. Phys. Sci. 1914, 90, 329-342. [CrossRef]

120. Irgens, F. Elements of Continuum Mechanics in General Coordinates; Springer Science and Business Media LLC: Berlin/Heidelberg, Germany, 2018; pp. 231-269.

121. Johnson, G.; Cook, W. A constitutive model and data for materials subjected to large strains, high strain rates, and high temperatures. In Proceedings of the 7th International Symposium on Ballistics, The Hague, The Netherlands, 19-21 April 1983; pp. 541-547.

122. Zerilli, F.J.; Armstrong, R.W. Dislocation-mechanics-based constitutive relations for material dynamics calculations. J. Appl. Phys. 1987, 61, 1816-1825. [CrossRef]

123. Zerilli, F.J. Dislocation mechanics-based constitutive equations. Met. Mater. Trans. A 2004, 35, 2547-2555. [CrossRef]

124. McDowell, D.L.; Miller, M.P.; Brooks, D.C. A unified creep-plasticity theory for solder alloys. In Fatigue of Electronic Materials; ASTM International: Conshohocken, PA, USA, 1994; pp. 42-59.

125. Lin, Y.; Chen, X.-M.; Wen, D.-X.; Chen, M.-S. A physically-based constitutive model for a typical nickel-based superalloy. Comput. Mater. Sci. 2014, 83, 282-289. [CrossRef]

126. Lin, Y.; Chen, M.-S.; Zhong, J. Prediction of $42 \mathrm{CrMo}$ steel flow stress at high temperature and strain rate. Mech. Res. Commun. 2008, 35, 142-150. [CrossRef]

127. Serajzadeh, S.; Taheri, A.K. Prediction of flow stress at hot working condition. Mech. Res. Commun. 2003, 30, 87-93. [CrossRef]

128. Khan, H.; Liu, H. Variable strain rate sensitivity in an aluminum alloy: Response and constitutive modeling. Int. J. Plast. 2012, 36, 1-14. [CrossRef] 
129. Baik, S.C.; Estrin, Y.; Kim, H.S.; Jeong, H.T.; Hellmig, R.J. Calculation of deformation behavior and texture evolution during equal channel angular pressing of IF steel using dislocation based modeling of strain hardening. Mater. Sci. Forum 2002, 408, 697-702. [CrossRef]

130. ToóthL, S.; Molinari, A.; Estrin, Y. Strain hardening at large strains as predicted by dislocation based polycrystal plasticity model. J. Eng. Mater. Technol. 2001, 124, 71-77. [CrossRef]

131. Baik, S.C.; Estrin, Y.; Kim, H.S.; Hellmig, R.J. Dislocation density-based modeling of deformation behavior of aluminium under equal channel angular pressing. Mater. Sci. Eng. A 2003, 351, 86-97. [CrossRef]

132. Galindo-Nava, E.; Rivera-Díaz-Del-Castillo, P. A thermodynamic theory for dislocation cell formation and misorientation in metals. Acta Mater. 2012, 60, 4370-4378. [CrossRef]

133. Mecking, H.; Kocks, U. Kinetics of flow and strain-hardening. Acta Met. 1981, 29, 1865-1875. [CrossRef]

134. Barlat, F. A simple model for dislocation behavior, strain and strain rate hardening evolution in deforming aluminum alloys. Int. J. Plast. 2002, 18, 919-939. [CrossRef]

135. Estrin, Y.; Kim, H.S. Modelling microstructure evolution toward ultrafine crystallinity produced by severe plastic deformation. J. Mater. Sci. 2007, 42, 1512-1516. [CrossRef]

136. Estrin, Y.; Tóth, L.S.; Brechet, Y.; Kim, H.S. Modelling of the evolution of dislocation cell misorientation under severe plastic deformation. Mater. Sci. Forum 2006, 503, 675-680. [CrossRef]

137. Roters, F.; Raabe, D.; Gottstein, G. Work hardening in heterogeneous alloys-A microstructural approach based on three internal state variables. Acta Mater. 2000, 48, 4181-4189. [CrossRef]

138. Hallberg, H.; Wallin, M.; Ristinmaa, M. Modeling of continuous dynamic recrystallization in commercial-purity aluminum. Mater. Sci. Eng. A 2010, 527, 1126-1134. [CrossRef]

139. Cheong, B.; Lin, J.; Ball, A. Modelling of hardening due to grain growth for a superplastic alloy. J. Mater. Process. Technol. 2001, 119, 361-365. [CrossRef]

140. Lin, J.; Dean, T. Modelling of microstructure evolution in hot forming using unified constitutive equations. J. Mater. Process. Technol. 2005, 167, 354-362. [CrossRef]

141. Kowalewski, Z.; Lin, J.; Hayhurst, D. Experimental and theoretical evaluation of a high-accuracy uni-axial creep testpiece with slit extensometer ridges. Int. J. Mech. Sci. 1994, 36, 751-769. [CrossRef]

142. Sun, Z.; Wu, H.; Cao, J.; Yin, Z. Modeling of continuous dynamic recrystallization of Al-Zn-Cu-Mg alloy during hot deformation based on the internal-state-variable (ISV) method. Int. J. Plast. 2018, 106, 73-87. [CrossRef]

143. Li, Y.; Gu, B.; Jiang, S.; Liu, Y.; Shi, Z.; Lin, J. A CDRX-based material model for hot deformation of aluminium alloys. Int. J. Plast. 2020, 134, 102844. [CrossRef]

Publisher's Note: MDPI stays neutral with regard to jurisdictional claims in published maps and institutional affiliations.

(C) 2020 by the authors. Licensee MDPI, Basel, Switzerland. This article is an open access article distributed under the terms and conditions of the Creative Commons Attribution (CC BY) license (http://creativecommons.org/licenses/by/4.0/). 